\title{
Waste Heat Recovery through Organic Rankine Cycles in the Bioethanol Separation Process
}

\author{
Brígido Jesús Hipólito-Valencia, ${ }_{\dagger}^{\dagger}$ María Vázquez-Ojeda, ${ }^{\ddagger}$ Juan Gabriel Segovia-Hernández, \\ and José María Ponce-Ortega*,† \\ ${ }^{\dagger}$ Chemical Engineering Department, Universidad Michoacana de San Nicolás de Hidalgo, Morelia, Mich. Mexico 58060 \\ ${ }^{\ddagger}$ Chemical Engineering Department, Universidad de Guanajuato, Guanajuato, Gto. Mexico 36050
}

ABSTRACT: The huge use of heating utilities is one of the main drawbacks associated with the azeotropic separation process for the bioethanol production. In this context, process integration through heat exchanger networks can be used to integrate the involved streams; however, the main problem in this scheme is that the streams that require cooling are at lower temperature that the ones that require heating, yielding very small opportunities for energy integration. Recently, the organic Rankine cycle has been proposed as an alternative for waste heat (i.e., heat at low temperature) recovery producing electric power. Therefore, in this paper is presented an optimization study for the energy integration in the azeotropic bioethanol separation process involving energy integration through heat exchanger networks incorporated into an organic Rankine cycle. A proper optimization approach is proposed to yield the solution with the minimum separation cost. Several separation sequences are used to demonstrate that incorporation of the organic Rankine cycle to energy integration in bioethanol production yields significant economic benefits. Furthermore, this integrated scheme improves the energy efficiency for the waste heat recovery, making more attractive the use of bioethanol.

\section{INTRODUCTION}

Decreasing greenhouse gas emissions (GHGE) has become an important global issue because the effects of climate change have negatively affected the whole world. The main source of GHGE is the use fossil fuels for heating, electricity generation, and transportation. One alternative to reduce these emissions is to substitute totally or partially fossil fuels with bioethanol, ${ }^{1,2}$ which is obtained from renewable resources. Furthermore, bioethanol can be implemented easily in the existing infrastructure and can substitute for methyl tert-butyl ether (MTBE) as an octane enhancer in gasoline engines. ${ }^{3}$ Nowadays, the largest bioethanol producer in the world is the United States, where bioethanol is produced mainly from corn, ${ }^{4}$ followed by Brazil, where the feedstock is sugar cane. ${ }^{5}$ However, the current methods for producing bioethanol (see Figure 1) use large amounts of energy in the separation process associated with the ethanol-water azeotropic mixture (because the ethanolgasoline blend has low water tolerance). ${ }^{6-8}$ Traditionally, the separation of the ethanol-water mixture is carried out through azeotropic distillation using benzene, pentane, or diethyl ether as solvent; another alternative is extractive distillation using ethylene glycol or gasoline. ${ }^{9,10}$ Furthermore, these technologies involve large capital and operating costs. ${ }^{7,8,11-15}$ In addition, bioreactors usually yield low concentrations of bioethanol, ${ }^{16,17}$ and huge utilities are required in the process (i.e., electricity, steam, and cooling water). For these reasons, until now bioethanol has not been yet economically competitive with respect to fossil fuels.

The azeotropic distillation process for the bioethanol-water mixture has associated several hot streams that require cooling and cold streams that require heating (Figure 1). ${ }^{6-10}$ In this context, energy integration through heat exchanger networks can be an attractive solution for reducing the external energy consumption in the separation process. ${ }^{18-25}$ Therefore, recently Vazquez-Ojeda et al. ${ }^{26}$ proposed integrating energetically the process streams involved in the bioethanol separation process through the SYNHEAT model. ${ }^{27-31}$ The main problem with this previous approach is that in the bioethanol separation process the hot streams are at low temperature, which decreases drastically the possibility of using these streams to heat the cold process streams that are at higher temperatures. In the approach by Vázquez-Ojeda et al. ${ }^{26}$ the integrated energy is low and so the reduction in the consumption of utilities. On the other hand, recently the organic Rankine cycle (ORC) has been proposed to recover waste heat and produce electric power; this unit is similar to the steam Rankine cycle (SRC), but it uses a refrigerant as working fluid. ${ }^{32-36}$ Desai and Bandyopadhyay ${ }^{37}$ have proposed integrating an ORC to a heat exchanger network (HEN) for waste heat recovery, and then Hipólito-Valencia et al. ${ }^{38-40}$ proposed superstructures and mathematical programming models for waste heat recovery through ORC in the synthesis of HEN. These approaches have shown that the ORC is able to recover a significant amount of waste heat, producing electric power and yielding significant economic improvements. Therefore, this paper proposes the use of an ORC integrated to HEN for energy integration during the bioethanol separation process. In this way, several optimized separation sequences using different solvents and configurations ${ }^{26,41}$ are integrated energetically involving the use of an ORC and using a new method for the energy integration.

Received: December 11, 2013

Revised: March 17, 2014

Accepted: March 26, 2014

Published: March 26, 2014 


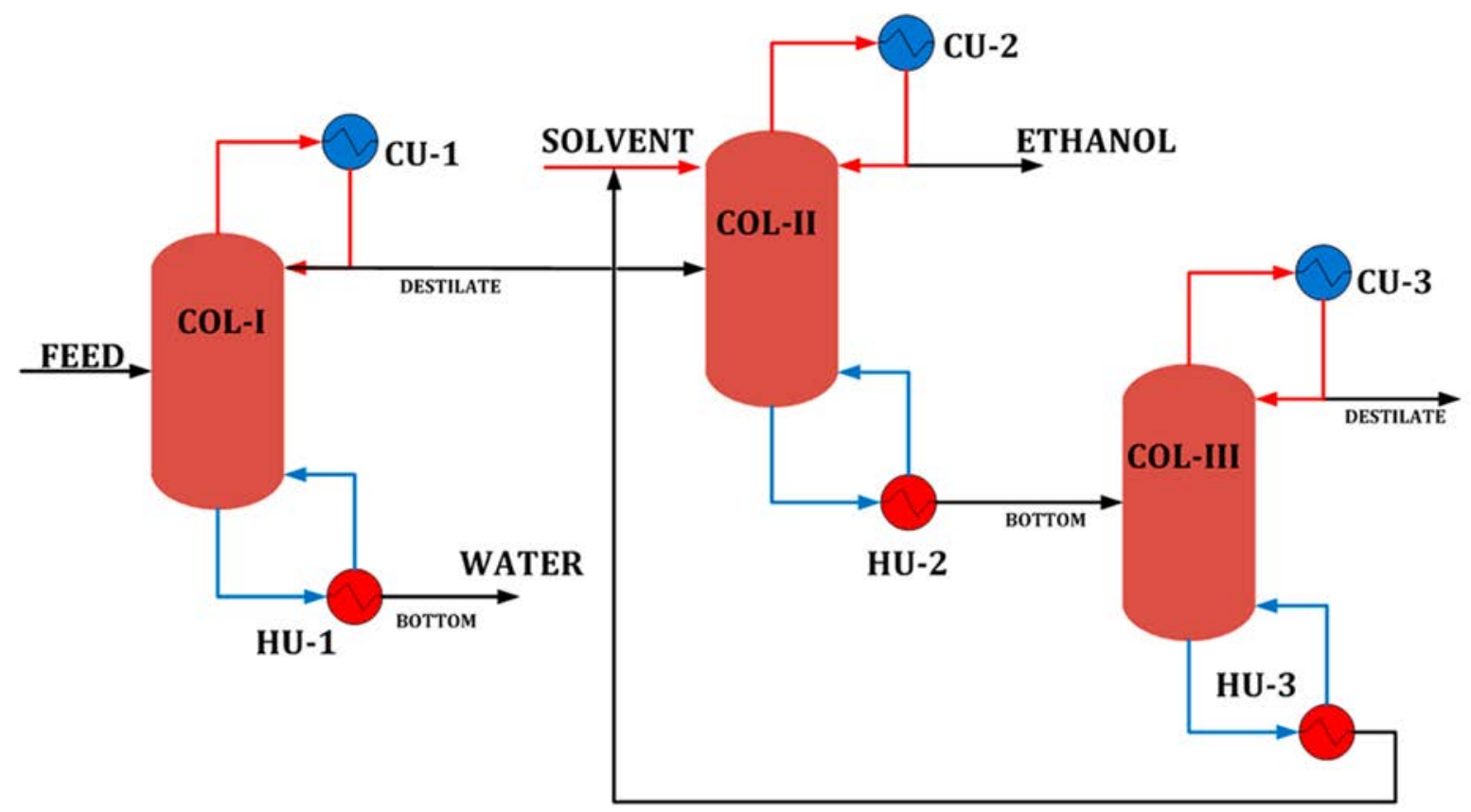

ETHANOL PROCESS

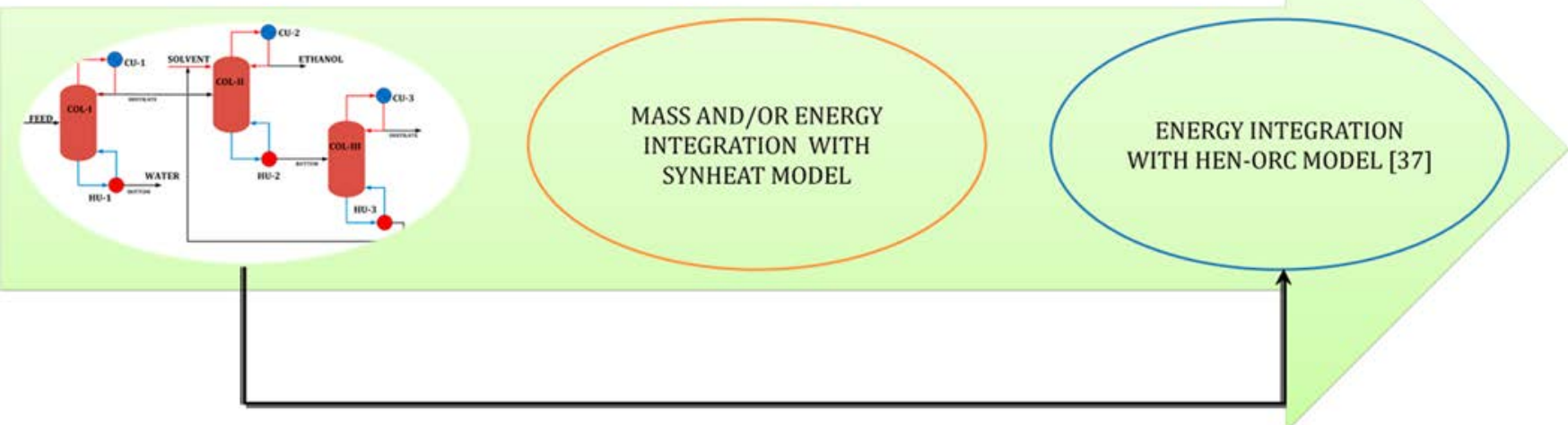

Figure 1. Schematic representation of the addressed problem.

\section{OPTIMIZATION METHODOLOGY}

The implemented approach can be stated as follows: bioethanol separation processes designed previously and reported in the literature have been taken (in this case were considered the sequences reported by Vázquez-Ojeda et al., ${ }^{41}$ where the operating conditions were optimized using evolutionary algorithms, and the sequences reported by Segovia-Hernandez et $\mathrm{al}^{42}$ ). From these designs are identified their hot and cold process streams as well as the flow rates, temperatures, and physical properties; these streams are then incorporated to the superstructure reported by Hipólito-Valencia et al., ${ }^{38}$ which includes an ORC to recover waste heat and produce electric power (HEN-ORC model). The superstructure is divided in stages (the number of stages corresponds to the maximum number of hot or cold process streams), and in each stage is allowed the heat exchange between any pair of hot and cold process streams (allowing in this way series, parallel, and seriesparallel arrangements). The superstructure also has two major
Table 1. Parameters for Optimization

\begin{tabular}{|c|c|}
\hline concept & value \\
\hline working fluid in the ORC & $\mathrm{R} 245 \mathrm{fa}$ \\
\hline factor used to annualize the inversion $k_{\mathrm{F}}\left(\right.$ year $\left.^{-1}\right)$ & 0.23 \\
\hline hours of operation per year (h/year) & 8000 \\
\hline$\Delta T_{\min }\left({ }^{\circ} \mathrm{C}\right)$ & 1 \\
\hline $\begin{array}{l}\text { exponent for the function of capital cost of exchangers } \\
\text { (dimensionless) }\end{array}$ & 0.65 \\
\hline unit cost for cooling utility (U.S. $\$ / \mathrm{kWh}$ ) & $1.27 \times 10^{-3}$ \\
\hline unit cost for heating utility (U.S.\$ $/ \mathrm{kWh}$ ) & 0.024 \\
\hline electricity cost, buy (U.S.\$/kWh) & 0.08 \\
\hline electricity cost, sell (U.S.\$/kWh) & 0.065 \\
\hline efficiency for energy production for the ORC & 0.144 \\
\hline overall efficiency for the pump of the ORC & 0.05 \\
\hline overall efficiency for the regenerator of the ORC & 0.04 \\
\hline unit fixed cost for heat exchangers (U.S.\$) & 0 \\
\hline unit variable cost for heat exchangers (U.S. $\$ / \mathrm{m}^{2}$ ) & 1650 \\
\hline
\end{tabular}




\section{Table 2. Data for Examples}

\begin{tabular}{|c|c|c|c|c|c|c|c|c|c|c|c|c|}
\hline \multicolumn{13}{|c|}{ Example 1} \\
\hline & \multicolumn{4}{|c|}{ DWC } & \multicolumn{4}{|c|}{ CED } & \multicolumn{4}{|c|}{ SVS } \\
\hline & \multicolumn{2}{|c|}{$\mathrm{TIN}^{a}$} & TOUT $^{b}$ & $\mathrm{FCp}^{c}$ & \multicolumn{2}{|c|}{ TIN } & TOUT & $\mathrm{FCp}$ & TIN & \multicolumn{2}{|c|}{ TOUT } & $\mathrm{FCp}$ \\
\hline $\mathrm{HPS}^{d}{ }^{d}$ & \multicolumn{2}{|c|}{78.19} & 77.19 & 2568 & \multicolumn{2}{|c|}{78.25} & 77.25 & 2646 & 78.19 & & 77.19 & 2640 \\
\hline HPS2 & & & 77.31 & 1982 & & & 77.31 & 1196 & 78.3 & & 77.3 & 1100 \\
\hline HPS3 & 100 & & 99.58 & 31 & & & 98.78 & 121 & & & & \\
\hline $\mathrm{AE}$ & 198 & & 30 & 4.075 & & & 30 & 3.22 & 288.7 & & 30 & 3.057 \\
\hline $\mathrm{CPS}^{e}$ & & & 100.95 & 3833 & & & 101.02 & 3917 & 99.98 & & 100.98 & 3902 \\
\hline CPS2 & 197 & & 198.08 & 1786 & & & 158.75 & 488 & 287.7 & & 288.71 & 982 \\
\hline CPS3 & & & & & & & 288 & 743 & & & & \\
\hline $\mathrm{CU}$ & 29 & & 39 & & & & 39 & & 29 & & 39 & \\
\hline $\mathrm{HU}$ & 300 & & 299 & & & & 299 & & 300 & & 299 & \\
\hline & & & & & & Example & & & & & & \\
\hline & & I & & & II & & & III & & & II & \\
\hline & TIN & TOUT & FCp & TIN & TOUT & FCp & TIN & TOUT & FCp & TIN & TOUT & FCp \\
\hline CSS & & & & & & & & & & & & \\
\hline HPS1 & 78 & 77 & 2400 & 78 & 77 & 2400 & 78 & 77 & 2400 & 78 & 77 & 3100 \\
\hline HPS2 & 78 & 77 & 1320 & 78 & 77 & 1320 & 78 & 77 & 1320 & 78 & 77 & 1300 \\
\hline HPS3 & 100 & 90 & 30 & 149 & 95 & 2.7 & 139 & 94 & 2.2 & 135 & 92 & 6.97 \\
\hline $\mathrm{AE}$ & 192 & 25 & 4.91 & 190 & 25 & 6 & 185 & 25 & 3.25 & 185 & 25 & 13.125 \\
\hline CPS1 & 100 & 101 & 3120 & 100 & 101 & 3120 & 100 & 101 & 1380 & 100 & 101 & 10100 \\
\hline CPS2 & 109 & 147 & 45 & 124 & 165 & 28.5 & 122 & 158 & 17.2 & 123 & 160 & 64.86 \\
\hline CPS3 & 177 & 192 & 29.3 & 181 & 190 & 27.7 & 172 & 185 & 11.53 & 173 & 185 & 41.6 \\
\hline CU & 18 & 32 & & 18 & 32 & & 18 & 32 & & 18 & 32 & \\
\hline HU & 300 & 250 & & 300 & 250 & & 300 & 250 & & 300 & 250 & \\
\hline OSS & & & & & & & & & & & & \\
\hline HPS1 & 85 & 80 & 364 & 85 & 80 & 246 & 87 & 81 & 1150 & 91 & 82 & 411.11 \\
\hline HPS2 & 78 & 77 & 2240 & 78 & 77 & 1500 & 78 & 77 & 7200 & 78 & 77 & 3200 \\
\hline HPS3 & 103 & 95 & 121.25 & 108 & 95 & 51.53 & 99 & 93 & 716.6 & 100 & 99 & 2500 \\
\hline $\mathrm{AE}$ & 188 & 25 & 3.19 & 192 & 25 & 2.33 & 185 & 25 & 15.625 & 196 & 25 & 7.6 \\
\hline CPS1 & 98 & 132 & 76.47 & 99 & 139 & 47 & 98 & 143 & 293.3 & 100 & 137 & 232.432 \\
\hline CPS2 & 102 & 112 & 245 & 101 & 113 & 137.5 & 103 & 114 & 736.36 & 105 & 112 & 514.285 \\
\hline CPS3 & 153 & 188 & 32.28 & 167 & 192 & 31.6 & 148 & 185 & 135.135 & 191 & 196 & 600 \\
\hline $\mathrm{CU}$ & 18 & 32 & & 18 & 32 & & 18 & 32 & & 18 & 32 & \\
\hline $\mathrm{HU}$ & 300 & 250 & & 300 & 250 & & 300 & 250 & & 300 & 250 & \\
\hline CSS-EI & & & & & & & & & & & & \\
\hline HPS1 & 78 & 77 & 1820 & 78 & 77 & 2410 & 78 & 77 & 680 & 78 & 77 & 3100 \\
\hline HPS2 & 78 & 77 & 2240 & 78 & 77 & 620 & 78 & 77 & 340 & 78 & 77 & 1300 \\
\hline HPS3 & 100 & 90 & 58 & 149 & 95 & 2.96 & 139 & 94 & 2 & 135 & 92 & 8.53 \\
\hline $\mathrm{AE}$ & 192 & 25 & 4.19 & 190 & 25 & 6.06 & 185 & 25 & 3.312 & 185 & 25 & 13.125 \\
\hline CPS1 & 100 & 101 & 2520 & 100 & 101 & 3120 & 100 & 101 & 1380 & 100 & 101 & 10100 \\
\hline CPS2 & 109 & 132 & 100.869 & 124 & 165 & 28.5 & 122 & 158 & 17.2 & 123 & 160 & 64.86 \\
\hline CPS3 & 177 & 192 & 75.3 & 181 & 190 & 27.7 & 172 & 185 & 11.53 & 173 & 185 & 41.6 \\
\hline $\mathrm{CU}$ & 18 & 32 & & 18 & 32 & & 18 & 32 & & 18 & 32 & \\
\hline $\mathrm{HU}$ & 300 & 250 & & 300 & 250 & & 300 & 250 & & 300 & 250 & \\
\hline OSS-EI & & & & & & & & & & & & \\
\hline HPS1 & 85 & 80 & 364 & 85 & 80 & 246 & 87 & 81 & 1150 & 91 & 81 & 370 \\
\hline HPS2 & 78 & 77 & 2240 & 78 & 77 & 1500 & 78 & 77 & 7200 & 78 & 77 & 3200 \\
\hline HPS3 & 103 & 95 & 121.25 & 108 & 95 & 51.53 & 99 & 93 & 710.5 & 100 & 99 & 2500 \\
\hline $\mathrm{AE}$ & 188 & 25 & 3.19 & 192 & 25 & 2.33 & 185 & 25 & 15.843 & 196 & 25 & 8.18 \\
\hline CPS1 & 98 & 132 & 76.47 & 99 & 139 & 47 & 98 & 143 & 291.06 & 99 & 137 & 228.94 \\
\hline CPS2 & 102 & 112 & 245 & 101 & 113 & 137.5 & 103 & 114 & 354.54 & 104 & 112 & 450 \\
\hline CPS3 & 153 & 188 & 32.28 & 167 & 192 & 31.6 & 148 & 185 & 135.135 & 190 & 196 & 500 \\
\hline $\mathrm{CU}$ & 18 & 32 & & 18 & 32 & & 18 & 32 & & 18 & 32 & \\
\hline $\mathrm{HU}$ & 300 & 250 & & 300 & 250 & & 300 & 250 & & 300 & 250 & \\
\hline & & & & & & nic Ranki & ne Cycle & & & & & \\
\hline & & condens & & & evapor & & & turbine & & & & \\
\hline & TIN & & TOUT & TIN & & $\overline{\text { OUT }}$ & TIN & & TOUT & TIN & & TOUT \\
\hline & 40 & & 30 & 40 & & 100 & & & 50.7 & 10 & & 20 \\
\hline
\end{tabular}


Table 2. continued

\begin{tabular}{|c|c|c|c|c|c|c|c|c|c|c|c|c|c|}
\hline \multicolumn{4}{|c|}{ example $1\left(\mathrm{kmol} \mathrm{h}^{-1}\right)$} & \multicolumn{4}{|c|}{ CSS and CSS-EI $\left(\mathrm{kmol} \mathrm{h}^{-1}\right)$} & \multicolumn{6}{|c|}{ OSS and OSS-EI $\left(\mathrm{kmol} \mathrm{h}^{-1}\right)$} \\
\hline & \multicolumn{2}{|c|}{ feed flow } & \multirow{2}{*}{$\frac{\text { solvent }}{\text { glycol }}$} & & \multicolumn{2}{|c|}{ feed flow } & \multirow{2}{*}{$\frac{\text { solvent }}{\text { ethylene glycol }}$} & & \multicolumn{2}{|c|}{ feed flow } & \multirow{2}{*}{$\frac{\text { solvent }}{\text { ethylene glycol }}$} & \multirow{2}{*}{\multicolumn{2}{|c|}{ FEED-II }} \\
\hline & ethanol & water & & & ethanol & water & & & ethanol & water & & & \\
\hline DWC & 85 & 1609.24 & 86.87 & I & 6.8 & 38.56 & 6.8 & I & 6.8 & 38.56 & 6.8 & octanol & 5.06 \\
\hline CED & 85 & 1609.24 & 48.7 & II & 4.54 & 40.82 & 8.44 & II & 4.54 & 40.82 & 8.44 & octanol & 4.16 \\
\hline SVS & 85 & 1609.24 & 46.28 & III & 2.27 & 43.09 & 4.55 & III & 2.27 & 43.09 & 4.55 & iso-octanol & 4.43 \\
\hline & & & & IV & 0.91 & 44.45 & 1.8 & IV & 0.91 & 44.45 & 1.8 & octanoic acid & 4 \\
\hline
\end{tabular}

${ }^{a_{\mathrm{TIN}}}\left({ }^{\circ} \mathrm{C}\right)$, inlet temperature. ${ }^{b} \mathrm{TOUT}\left({ }^{\circ} \mathrm{C}\right)$, outlet temperature. ${ }^{c} \mathrm{FCp}\left(\mathrm{kW} /{ }^{\circ} \mathrm{C}\right)$, heat capacity flow rate. ${ }^{d} \mathrm{HPS}$, hot process stream. ${ }^{e} \mathrm{CPS}$, cold process stream.

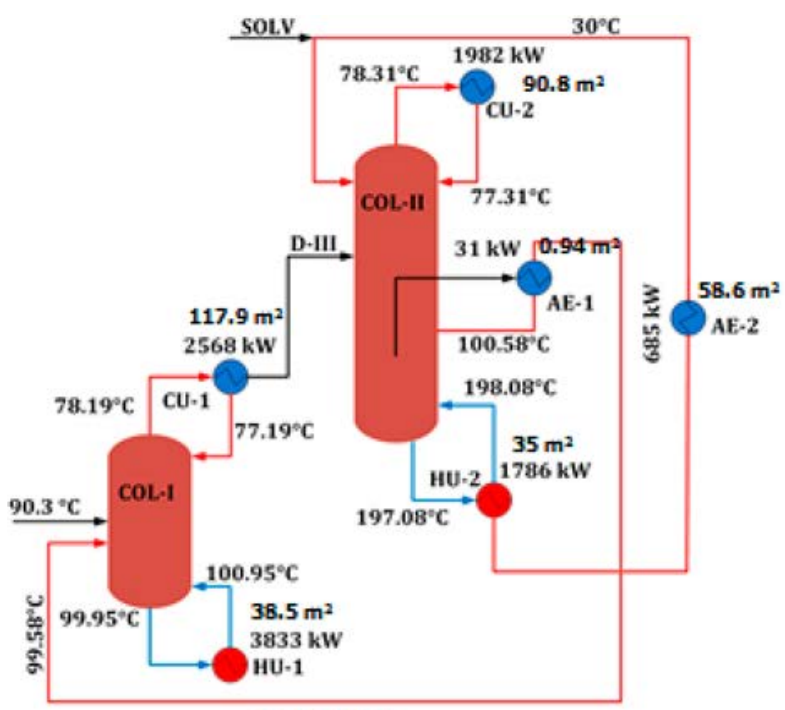

A) DWC

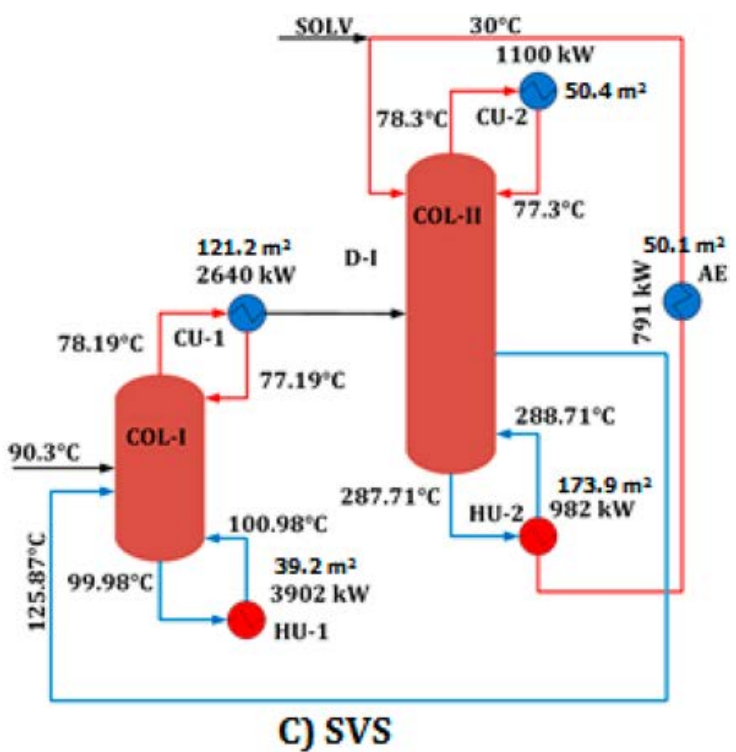

C) SVS

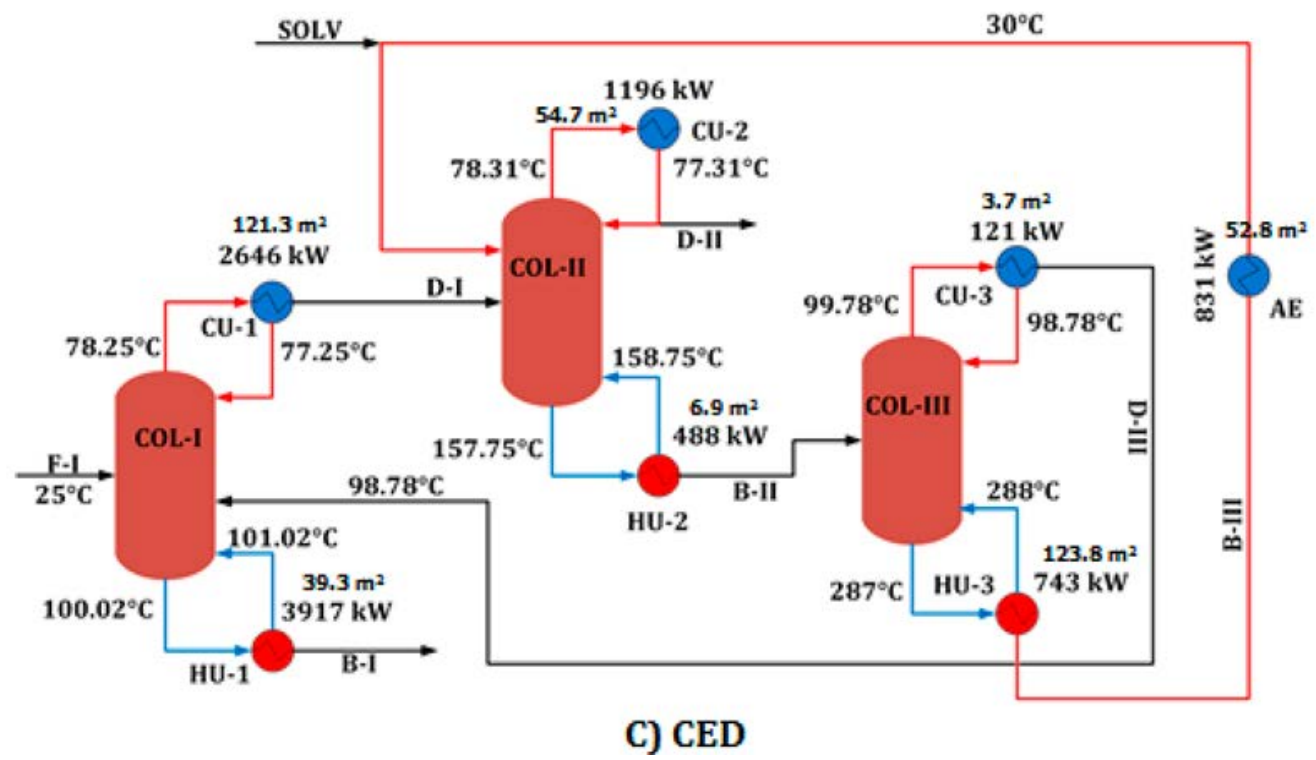

Figure 2. Configurations for the WEIS sequences.

zones: a high-temperature zone in which there is heat exchange (i.e., process-to-process heat-exchange zone) and a lowtemperature zone that considers the integration of the ORC into the process to generate shaft work. In this context, for the hot process streams there are potential heat exchangers that transfer waste heat from the HEN to run the organic Rankine cycle (evaporators), and in the cold process streams also there are potential heat exchangers that receive heat at low temperature from the condenser of the ORC (condensers). The remaining heat exiting from the ORC is removed using cooling utilities. To satisfy the utility demands, there are considered at the cold and hot extremes of the superstructure auxiliary cooling and heating, respectively. The existences for the exchangers are optimized through binary variables. The temperatures for the process streams through the superstructure are optimization variables (continuous variables), and 


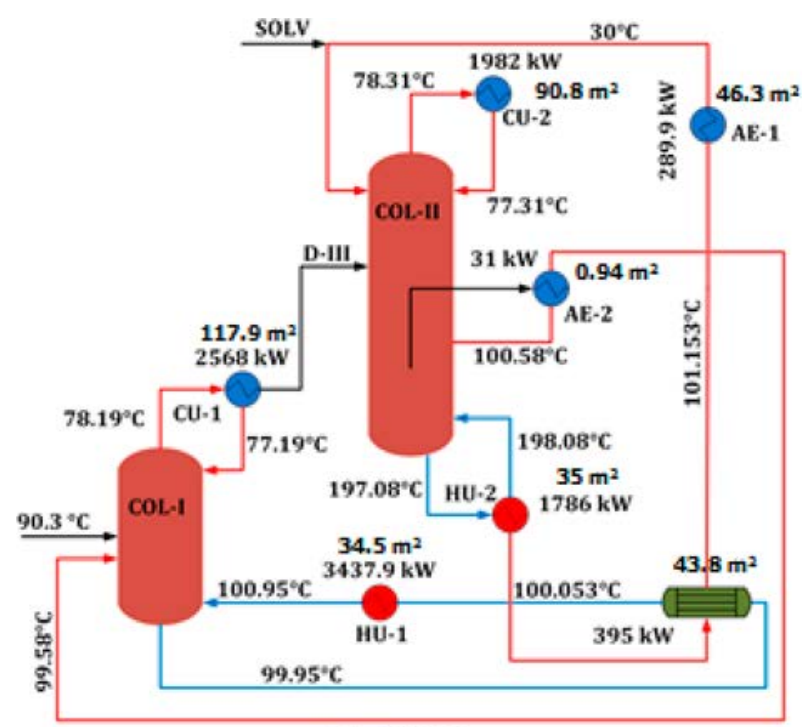

A) DWC

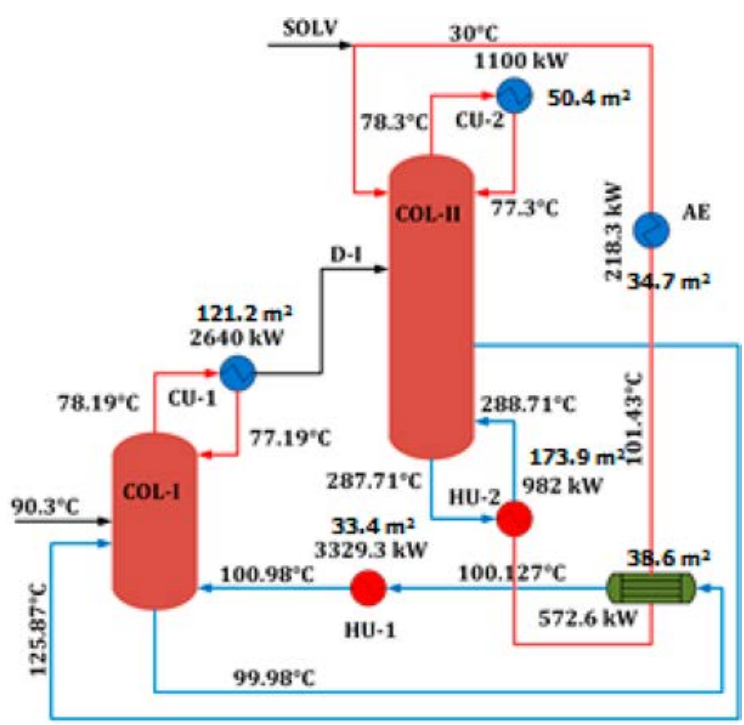

C) SVS

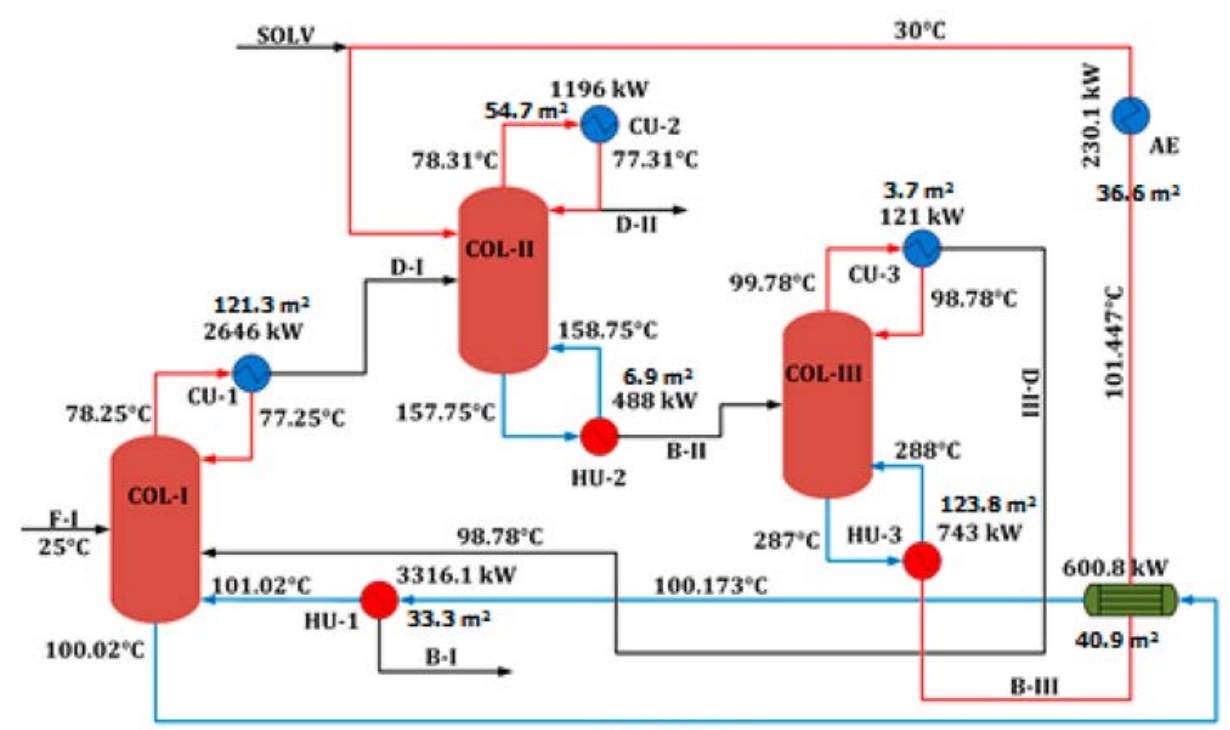

B) CED

Figure 3. Configurations using the SYNHEAT model.

only a limit for the temperature difference for any match in the superstructure is imposed as $\Delta T_{\min }=1{ }^{\circ} \mathrm{C}$ (it should be noted that this $\Delta T_{\min }$ is just a lower limit, but the optimization process accounting simultaneously for the capital and operating costs must determine the optimal temperature differences for each match). This limit is just a feasibility constraint, but this does not fix the heat recovered; the model by Hipólito-Valencia et al. $^{38}$ minimizes the total annual cost accounting simultaneously for the utility costs and capital costs for equipment of the HEN and ORC (turbine, pump, regenerator, evaporators, and condensers) as well as the revenue from the sale of the power produced by the ORC.

The HEN-ORC model by Hipólito-Valencia et al. ${ }^{38}$ includes overall energy balances for each stream, energy balances for each stage of the superstructure, energy balances for the hot and cold utilities, energy balances for evaporators and condensers in the ORC, temperature feasibility constraints, logical relationships to determine the existence of the units required, temperature differences for the heat transfer units when these exist, energy balances for the ORC, and the objective function. This model is formulated as a mixed integer nonlinear programming (MINLP) optimization problem, and this was coded in the GAMS software. ${ }^{43}$

\section{CASE STUDY}

The first example corresponds to the bioethanol azeotropic distillation process taking into account a solution without energy integration (WEIS); then the cases when the energy integration through the SYNHEAT and the HEN-ORC models are considered. The second example considers the configurations for the azeotropic distillation obtained by VázquezOjeda et al., ${ }^{26}$ where there are reported conventional separation sequences (CSS) and optional separation sequences (OSS), which are energetically integrated considering the proposed scheme involving the HEN-ORC system. Moreover, VázquezOjeda et al. $^{26}$ also presented the energy integration with the SYNHEAT model, to which these solutions also are incorporated in the HEN-ORC model. For the first example, 


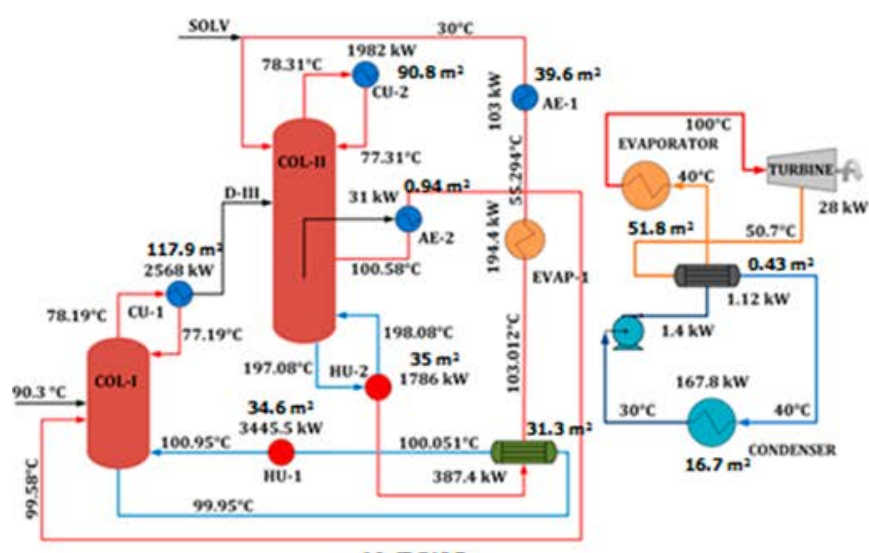

A) DWC

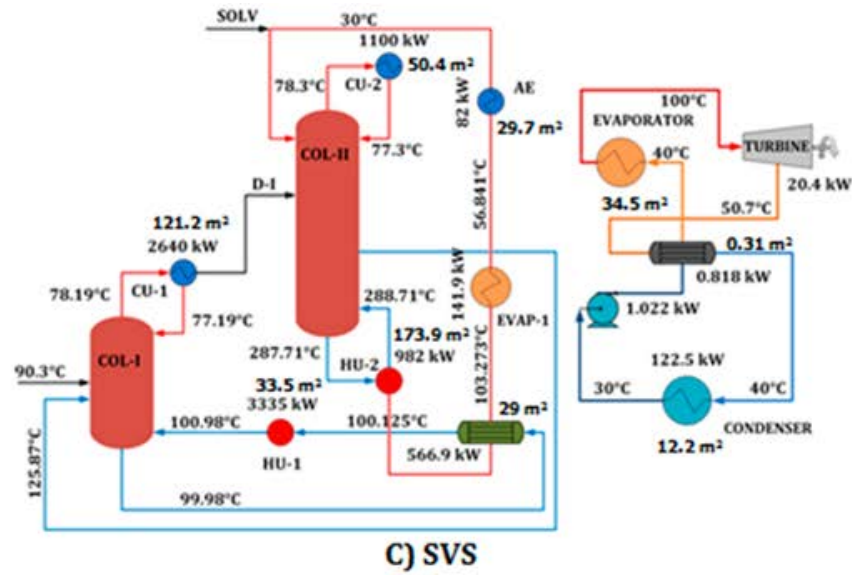

C) SVS

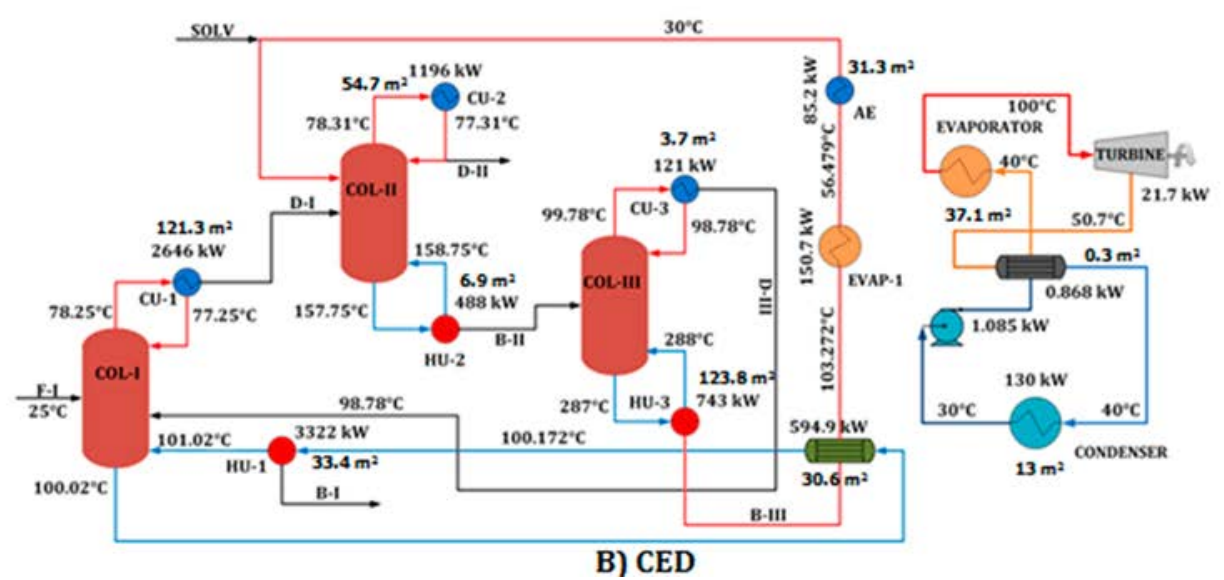

Figure 4. Optimal solution for ethanol process using the HEN-ORC model.

cooling water at $29-39{ }^{\circ} \mathrm{C}$ was considered the cooling utility, whereas steam at $300{ }^{\circ} \mathrm{C}$ was considered the heating utility. For the second example, the cooling utility is at $18-32{ }^{\circ} \mathrm{C}$, whereas the steam is at $300-250{ }^{\circ} \mathrm{C}$. The unit steam price is U.S. $\$ 0.024012 / \mathrm{kWh}$, the unit electric power cost is U.S. $\$ 0.065 / \mathrm{kWh}$, and the unit cost for the electricity for the pump is U.S. $\$ 0.08 / \mathrm{kWh}$, the unit cooling water cost is U.S. $\$ 1.2744 \times 10^{-3} / \mathrm{kWh}$. The working fluid in the ORC is $\mathrm{R} 245 \mathrm{fa}$, and the efficiency factors for ORC, pump of the ORC, and regenerator are 0.144, 0.05, and 0.04, respectively. $\Delta T_{\min }=1{ }^{\circ} \mathrm{C}$, and the operation time for the plant is $8000 \mathrm{~h} /$ year. The economic information used is shown in Table 1, and the data for the involved streams are shown in Table 2.

Example 1. Figure 2 shows the following separation sequences without energy integration: (a) intensified extractive distillation sequence with dividing wall column and vapor side stream (DWC); (b) conventional extractive distillation sequence (CED); and (c) intensified extractive distillation sequence with vapor side stream (SVS). The streams that require heating and cooling are identified from these figures; then, the SYNHEAT model and the proposed HEN-ORC model are considered to integrate these streams. This way, Figure 3 presents the optimal designs using the SYNHEAT model to integrate the process, whereas Figure 4 shows the optimal solution obtained using the HEN-ORC model. Table 3 presents the energy consumptions of heating, cooling, and auxiliary equipment, the number of exchangers, the transferred total heat within the HEN, the transferred heat to the ORC, and the produced power for the different scenarios with and without energy integration.

Reductions should be noted in the consumption of utilities in the separation sequences with the SYNHEAT model, specifically in the hot utility of $7.03,11.67$, and $11.72 \%$ for the DWC, CED, and SVS columns, respectively. These percentages are slightly higher than the ones obtained with the HEN-ORC model. However, the HEN-ORC model presents a major saving for the auxiliary equipment with $81.28,89.74$, and $89.63 \%$ for the DWC, CED, and SVS sequences, respectively (for the SYNHEAT model there are 55.18\% DWC, $72.31 \%$ CED, and $72.4 \%$ SVS energy savings for auxiliary equipment (AE)). Then, although the total capital cost for the HEN-ORC solution is higher due to the ORC incorporated into the ethanol process, this obtains incomes for sales of electric power for all of the sequences (U.S.\$14561/year for DWC, U.S.\$11285/year for CED, and U.S.\$10630/year for SVS) and reduces the total operating cost by $6.86,11.55$, and $11.6 \%$ for DWC, CED, and SVS, respectively. These profits generate total annual costs that are $6.86,11.55$, and $11.6 \%$ lower than the WEIS solution and $0.4,0.53$, and $0.44 \%$ lower than the one incorporated into the SYNHEAT model for the DWC, CED, and SVS sequences, respectively. Finally, the incorporation of the ORC to the bioethanol separation process generates a return on investment of $107.54,103.21$, and $102.1 \%$ for the sequences DWC, CED, and SVS, respectively. Note that the cost for the ORC considers cooling, pumping, cooler, evaporators, pump, regenerator, and turbine. Table 4 shows the associated costs for example 1 . 
Table 3. Energy Requirements for the Conventional Separation Sequences for DWC, CED, and SVS Columns

\begin{tabular}{|c|c|c|c|}
\hline concept/sequence & DWC & CED & SVS \\
\hline \multicolumn{4}{|c|}{ WEIS (kW) } \\
\hline heating & 5619 & 5148 & 4884 \\
\hline cooling & 4550 & 3963 & 3740 \\
\hline auxiliary equipment & 716 & 831 & 791 \\
\hline \multicolumn{4}{|c|}{ SYNHEAT Model (kW) } \\
\hline heating & 5223.9 & 4547.1 & 4311.3 \\
\hline cooling & 4550 & 3963 & 3740 \\
\hline auxiliary equipment & 320.9 & 230.1 & 218.3 \\
\hline no. of heat transfer units & 1 & 1 & 1 \\
\hline total heat transferred with HEN & 395 & 600.8 & 572.6 \\
\hline \multicolumn{4}{|c|}{ HEN-ORC Model $(\mathrm{kW})$} \\
\hline heating & 5231.5 & 4553 & 4317 \\
\hline cooling & 4550 & 3963 & 3740 \\
\hline auxiliary equipment & 134 & 85.2 & 82 \\
\hline no. of heat transfer units & 1 & 1 & 1 \\
\hline total heat transferred with HEN & 387.4 & 594.9 & 566.9 \\
\hline heat transferred to ORC & 194.4 & 150.7 & 141.9 \\
\hline produced power & 28 & 21.7 & 20.4 \\
\hline \multicolumn{4}{|c|}{ Savings (\%) } \\
\hline \multicolumn{4}{|c|}{ SYNHEAT model with respect to WEIS } \\
\hline heating & 7.03 & 11.67 & 11.72 \\
\hline cooling & 0 & 0 & 0 \\
\hline auxiliary equipment & 55.18 & 72.31 & 72.4 \\
\hline \multicolumn{4}{|c|}{ HEN-ORC system with respect to WEIS } \\
\hline heating & 6.89 & 11.55 & 11.6 \\
\hline cooling & 0 & 0 & 0 \\
\hline auxiliary equipment & 81.28 & 89.74 & 89.63 \\
\hline
\end{tabular}

Example 2. The following schemes are considered for this example: conventional separation sequences based on distillation columns (CSS), hybrid configuration based on liquid-liquid extraction and extractive distillation (OSS), conventional separation sequence for purification of ethanol with mass and energy integration (CSS-EI), and hybrid configuration based on liquid-liquid extraction and extractive distillation with mass and energy integration (OSS-EI). The two last cases use the SYNHEAT model. ${ }^{26}$ All of the designs are for purification of ethanol, and each ethanol process is applied to the HEN-ORC model. Figure 5 shows the WEIS solution for the sequence CSS, whereas Figure 6 presents the optimal solution using the HEN-ORC model.

For the CSS scheme, the HEN-ORC model yields the following energy savings: $8.29,14.51,16.32$, and $10.16 \%$ for heating and $82.76,82.93,80.73$, and $84.39 \%$ for the auxiliary equipment with respect to sequences I, II, III, and IV, respectively. Moreover, there are reductions by $4.71 \%$ for sequence II, $8.92 \%$ for sequence III, and $6.38 \%$ for sequence IV in cooling utility (considering the cooling water for the ORC). This solution recovers waste heat producing $34,45,24.3$, and $107.9 \mathrm{~kW}$ of electricity for the configurations CSS I, II, III, and IV, respectively. The return on investment for the ORC is 111, 115,105 , and $134 \%$ for sequences I, II, III, and IV, respectively. The electric power produced generates profits between U.S. $\$ 18094 /$ year and U.S.\$56148/year, yielding a total annual cost of $8.52 \%$ (I), $14.77 \%$ (II), $16.28 \%$ (III), and $11.05 \%$ (IV) lower than the WEIS solution.

For the hybrid configuration (Figure 7) based on liquidliquid extraction and extractive distillation (OSS), application of the HEN-ORC model (Figure 8) achieves energy savings of 19.28 and $19.7 \%$ in the cooling water required for sequences I and II; for the heating utility there are obtained savings of 8.31 , $13.15,4.92$, and $4.65 \%$ in configurations I, II, III, and IV, respectively. There are energy savings of $84.67 \%$ for sequence I, $83.66 \%$ for sequence II, $84.64 \%$ for sequence III, and $84.33 \%$ for sequence IV in the auxiliary equipment. Furthermore, in the solutions for the integrated HEN-ORC there are total areas

Table 4. Associated Cost with and without Energy Integration for DWC, CED, and SVS Sequences

\begin{tabular}{|c|c|c|c|c|c|c|c|c|c|}
\hline \multirow{3}{*}{$\begin{array}{c}\text { sequence: } \\
\text { type of integration: } \\
\text { area }\left(\mathrm{m}^{2}\right) \text { : }\end{array}$} & \multicolumn{3}{|c|}{ DWC } & \multicolumn{3}{|c|}{ CED } & \multicolumn{3}{|c|}{ SVS } \\
\hline & WEIS & SYNHEAT & HEN-ORC & WEIS & SYNHEAT & HEN-ORC & WEIS & SYNHEAT & HEN-ORC \\
\hline & 341 & 369 & 419 & 402 & 421 & 456 & 435 & 452 & 485 \\
\hline \multicolumn{10}{|c|}{ Operating Cost (U.S.\$/year) } \\
\hline HEN heating & $1,079,387$ & $1,003,505$ & $1,004,960$ & 988,910 & 873,484 & 874,613 & 938,196 & 828,201 & 829,284 \\
\hline HEN cooling & 46704 & 46704 & 46704 & 40403 & 40403 & 40403 & 38130 & 38130 & 38130 \\
\hline auxiliary equipment cooling & 6983 & 2956 & 1050 & 8472 & 2346 & 869 & 8064 & 2226 & 836 \\
\hline ORC cooling & & & 1711 & & & 1326 & & & 1249 \\
\hline pumping & & & 896 & & & 694 & & & 654 \\
\hline \multicolumn{10}{|c|}{ Capital Cost (U.S.\$/year) } \\
\hline HEN exchangers & & 4430 & 3559 & & 4235 & 3512 & & 4083 & 3389 \\
\hline HEN heaters & 7903 & 7625 & 5987 & 14165 & 13742 & 10450 & 14972 & 14569 & 12169 \\
\hline HEN coolers & 15907 & 15907 & 15907 & 14600 & 14600 & 14600 & 13435 & 13435 & 13435 \\
\hline auxiliary equipment & 5354 & 4591 & 4148 & 5001 & 3943 & 3560 & 4837 & 3811 & 3442 \\
\hline ORC cooler & & & 2373 & & & 2011 & & & 1934 \\
\hline evaporator & & & 4942 & & & 3981 & & & 3796 \\
\hline \multicolumn{10}{|l|}{ condenser } \\
\hline pump & & & 77 & & & 61 & & & 58 \\
\hline regenerator & & & 220 & & & 186 & & & 179 \\
\hline turbine & & & 3321 & & & 2674 & & & 2541 \\
\hline income from sale of electricity & & & 14561 & & & 11285 & & & 10630 \\
\hline total operating cost & $1,133,075$ & $1,053,166$ & $1,055,323$ & $1,037,785$ & 916,234 & 917,907 & 984,391 & 868,558 & 870,154 \\
\hline total capital cost & 29164 & 32555 & 40537 & 33767 & 36521 & 41039 & 33245 & 35899 & 40946 \\
\hline total annual cost & $1,162,239$ & $1,085,721$ & $1,081,298$ & $1,071,553$ & 952,755 & 947,661 & $1,017,636$ & 904,457 & 900,470 \\
\hline
\end{tabular}




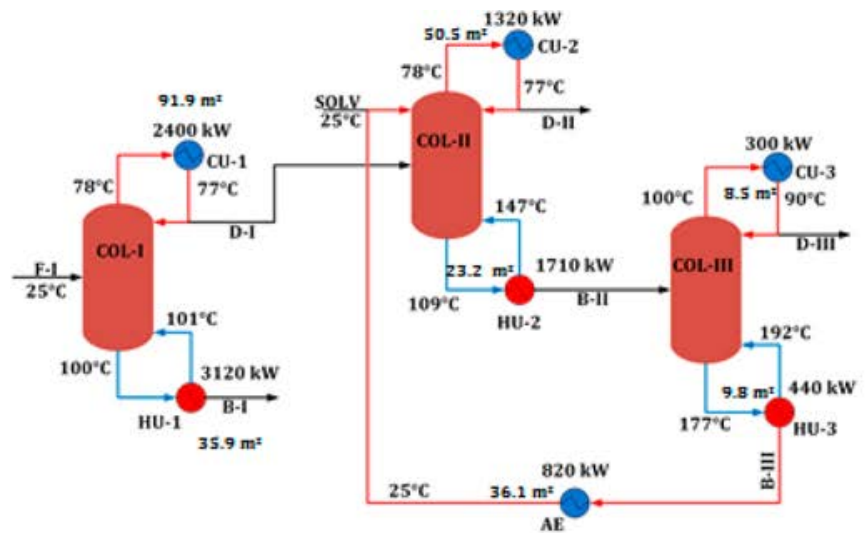

A) CSS-I

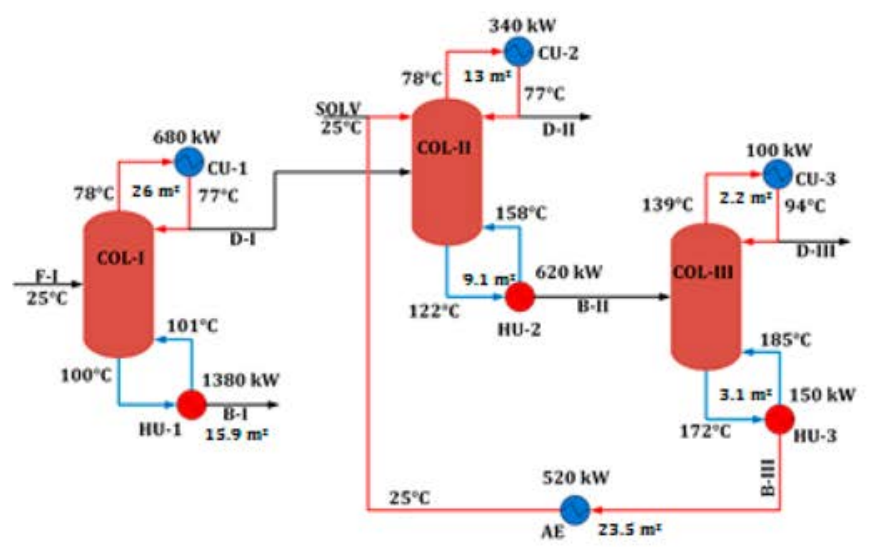

C) CSS-III

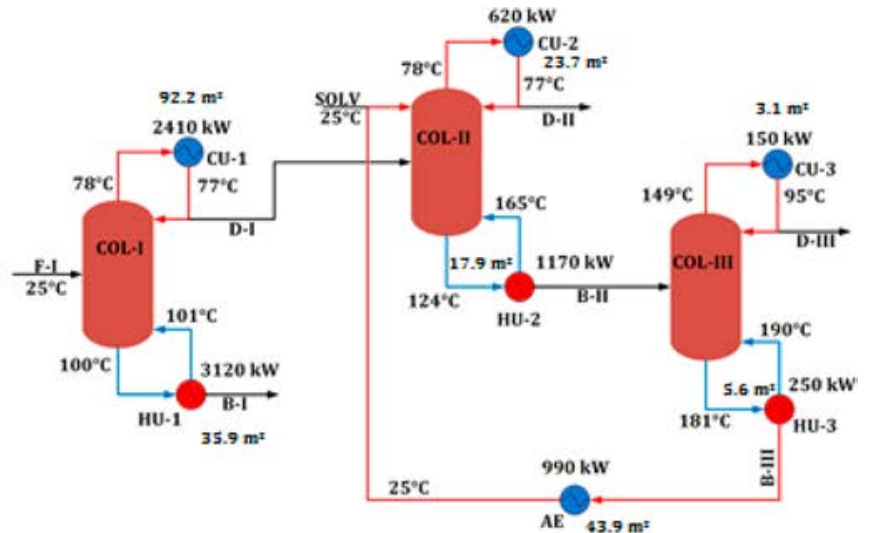

B) CSS-II

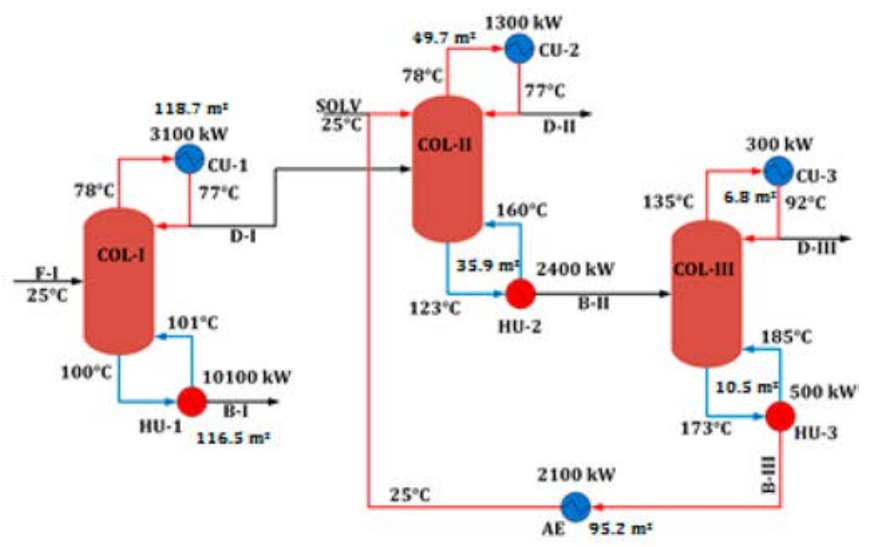

D) CSS-IV

Figure 5. Conventional separation sequences based on distillation columns (WEIS).

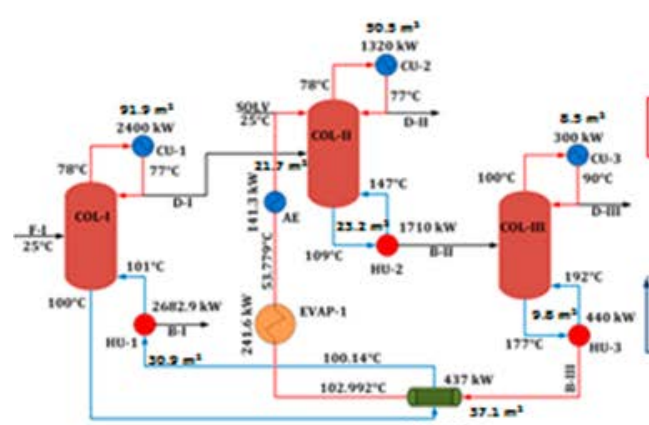

A) CSS-1

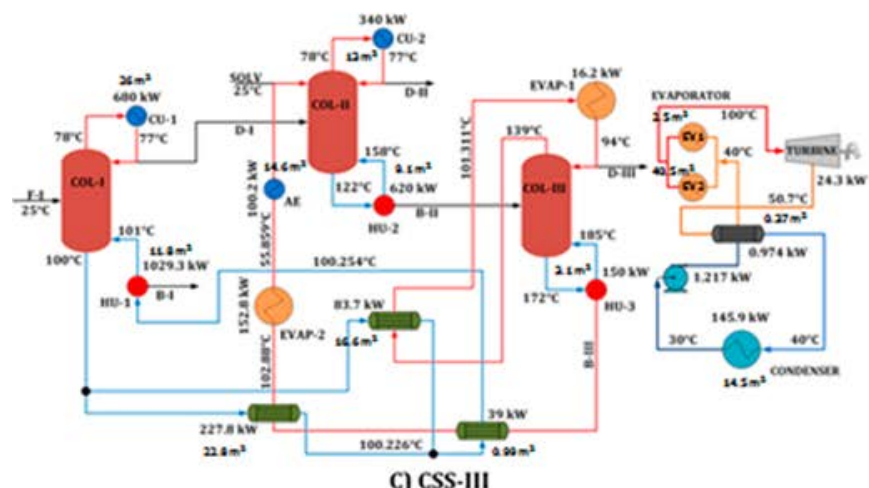

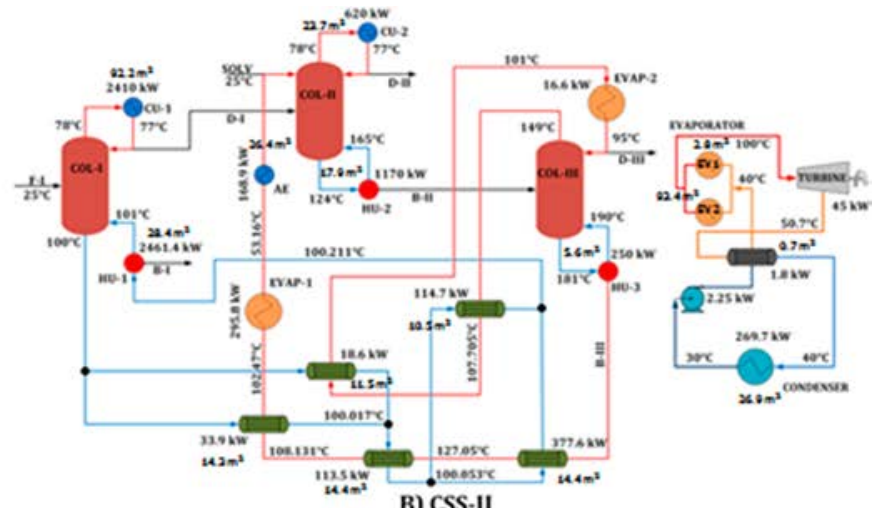

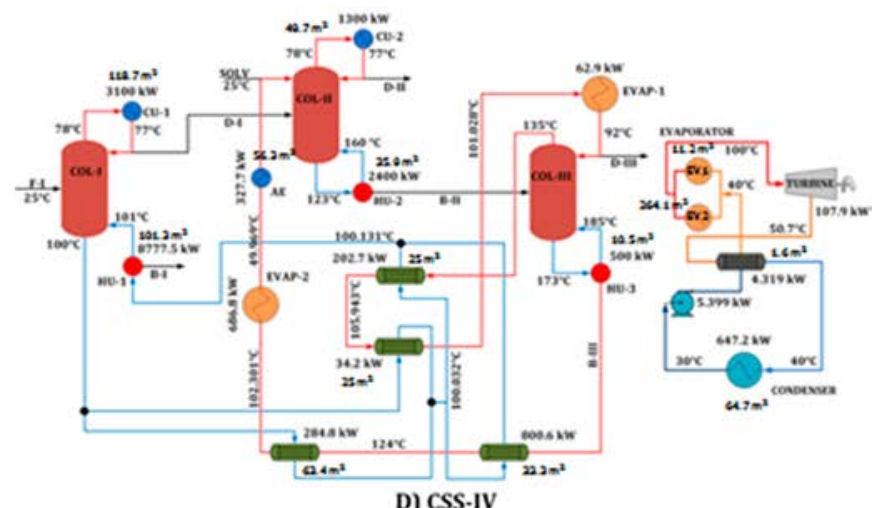

Figure 6. Conventional separation sequences based on distillation columns with energy integration using HEN-ORC model. 


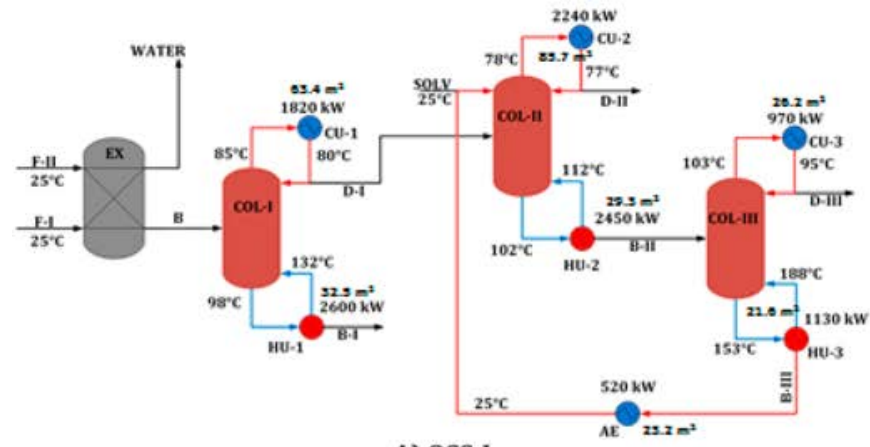

A) 0SS-1

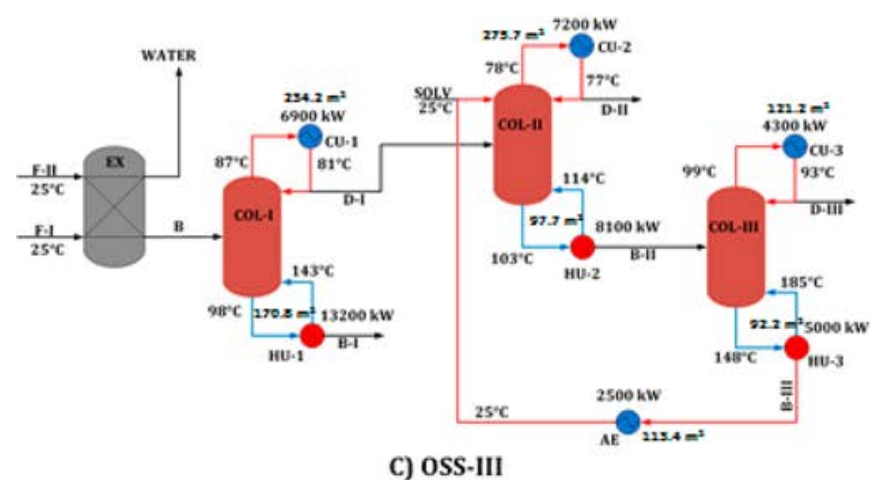

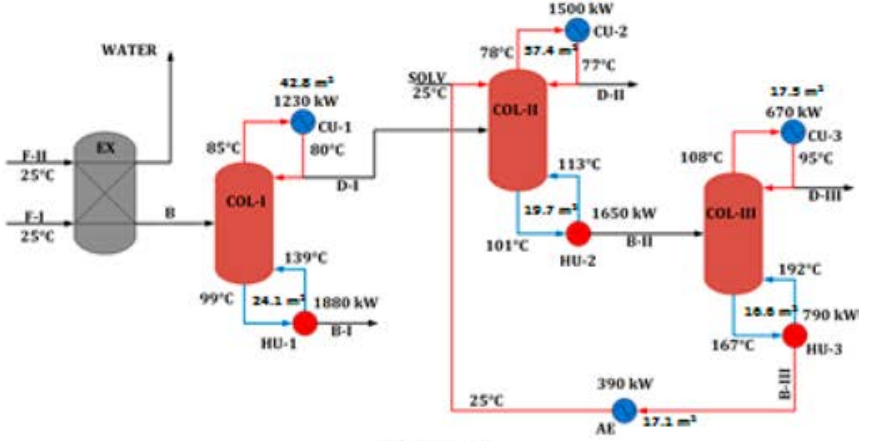

B) OSS-II

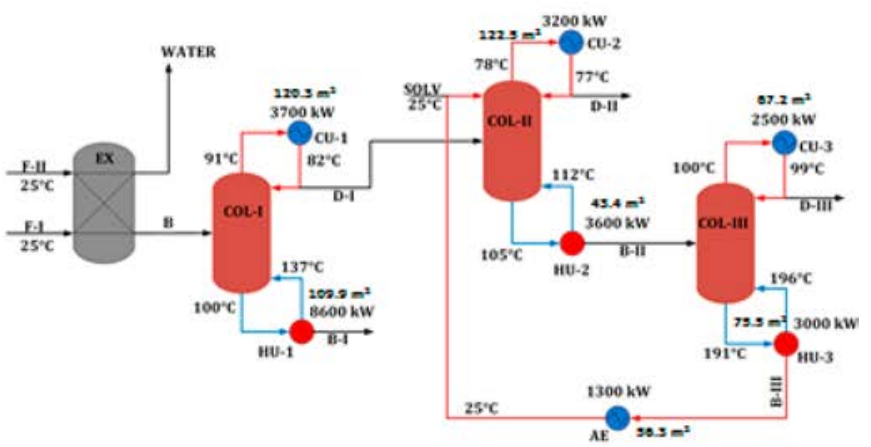

D) OSS-IV

Figure 7. Hybrid configuration based on liquid-liquid extraction and extractive distillation (WEIS).

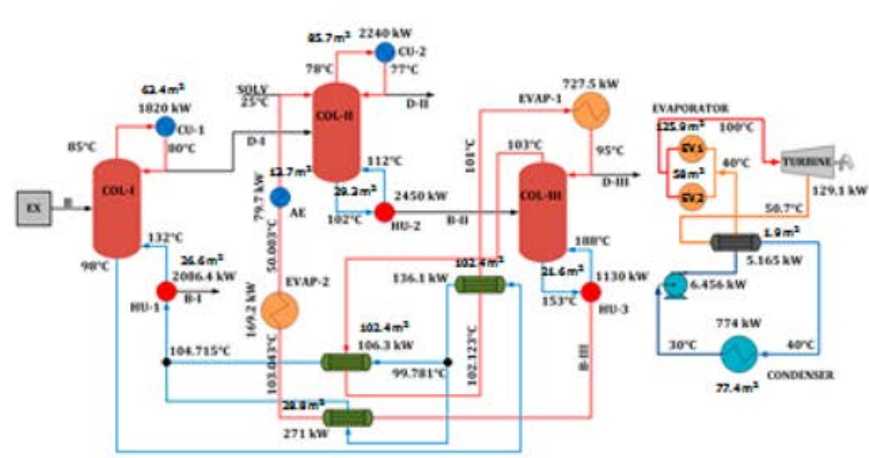

A) 0SS-1

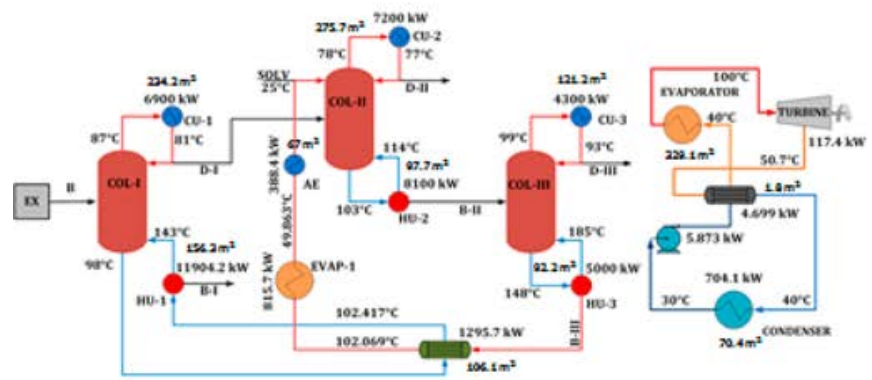

C) oss-III

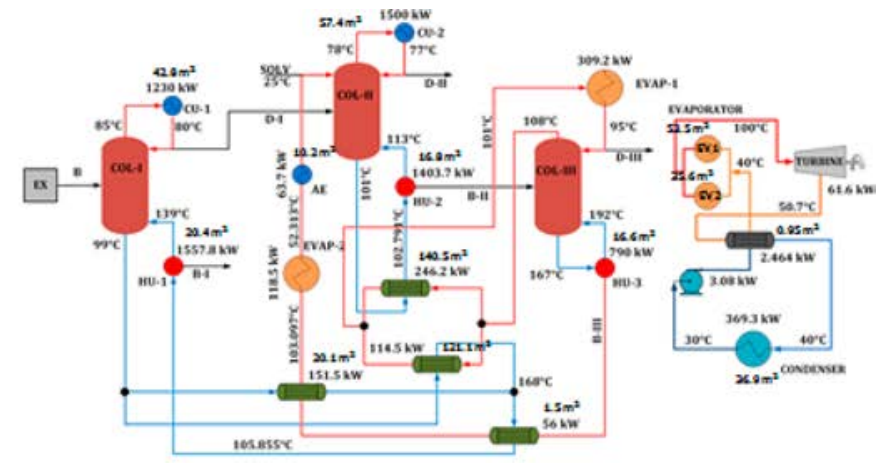

B) OSS-II

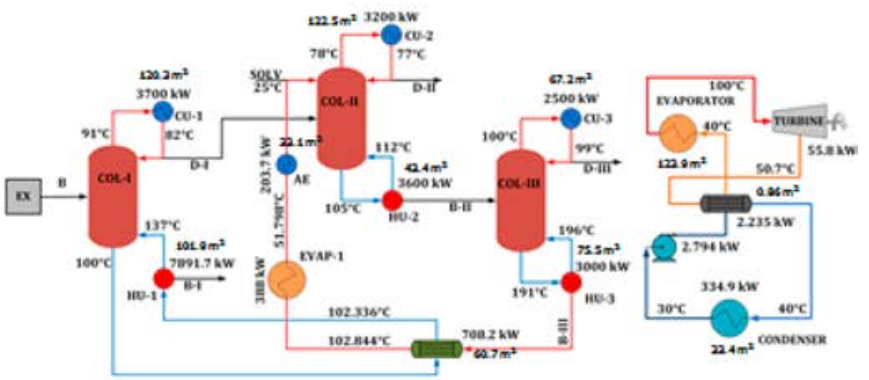

D) OsS-IV

Figure 8. Hybrid configuration based on liquid-liquid extraction and extractive distillation applying the HEN-ORC integration.

$61.75,65.99,28.77$, and $23.97 \%$ greater than the one obtained in the WEIS configurations for the different sequences; nevertheless, the waste heat recovered in the auxiliary equipment is used in the ORC $(896.7,427.8,815.7$, and 388 $\mathrm{kW})$ to yield $129.1,61.6,117.4$, and $55.8 \mathrm{~kW}$ of electric power.
Then, the incomes obtained reduce the total annual cost by $10.35,13.33,5.41$, and $5.01 \%$ with respect to the WEIS solution for sequences I, II, III, and IV, respectively. The return on investment for the ORC is 157, 134, 134, and $120 \%$ for sequences I, II, III, and IV, respectively. Table 5 presents the 
Table 5. Energy Requirements for CSS and OSS with and without Energy Integration

\begin{tabular}{|c|c|c|c|c|c|c|c|c|}
\hline \multirow[b]{2}{*}{ concept/sequence: } & \multicolumn{4}{|c|}{ CSS } & \multicolumn{4}{|c|}{ OSS } \\
\hline & I & II & III & IV & I & II & III & IV \\
\hline \multicolumn{9}{|c|}{ WEIS (kW) } \\
\hline heating & 5270 & 4540 & 2150 & 13000 & 6180 & 4320 & 26300 & 15200 \\
\hline cooling & 4020 & 3180 & 1120 & 4700 & 5030 & 3400 & 18400 & 9400 \\
\hline auxiliary equipment & 820 & 990 & 520 & 2100 & 520 & 390 & 2500 & 1300 \\
\hline \multicolumn{9}{|c|}{ HEN-ORC Model (kW) } \\
\hline heating & 4833 & 3881 & 1799 & 11678 & 5666.4 & 3751.6 & 25004.2 & 14491.7 \\
\hline cooling & 4020 & 3030 & 1020 & 4400 & 4060 & 2730 & 18400 & 9400 \\
\hline auxiliary equipment & 141.3 & 168.9 & 100.2 & 327.7 & 79.7 & 63.7 & 388.4 & 203.7 \\
\hline no. of exchangers & 1 & 5 & 3 & 4 & 3 & 4 & 1 & 1 \\
\hline total heat transferred with HEN & 437 & 658.5 & 350.6 & $1,322.4$ & 513.5 & 568.3 & $1,295.7$ & 708.2 \\
\hline total heat transferred to ORC & 241.6 & 312.5 & 169 & 749.8 & 896.7 & 427.8 & 815.7 & 388 \\
\hline power produced & 34 & 45 & 24.3 & 107.9 & 129.1 & 61.6 & 117.4 & 55.8 \\
\hline \multicolumn{9}{|c|}{ Savings (\%) } \\
\hline heating & 8.29 & 14.51 & 16.32 & 10.16 & 8.31 & 13.15 & 4.92 & 4.65 \\
\hline cooling & 0 & 4.71 & 8.92 & 6.38 & 19.28 & 19.7 & 0 & 0 \\
\hline auxiliary equipment & 82.76 & 82.93 & 80.73 & 84.39 & 84.67 & 83.66 & 84.64 & 84.33 \\
\hline
\end{tabular}

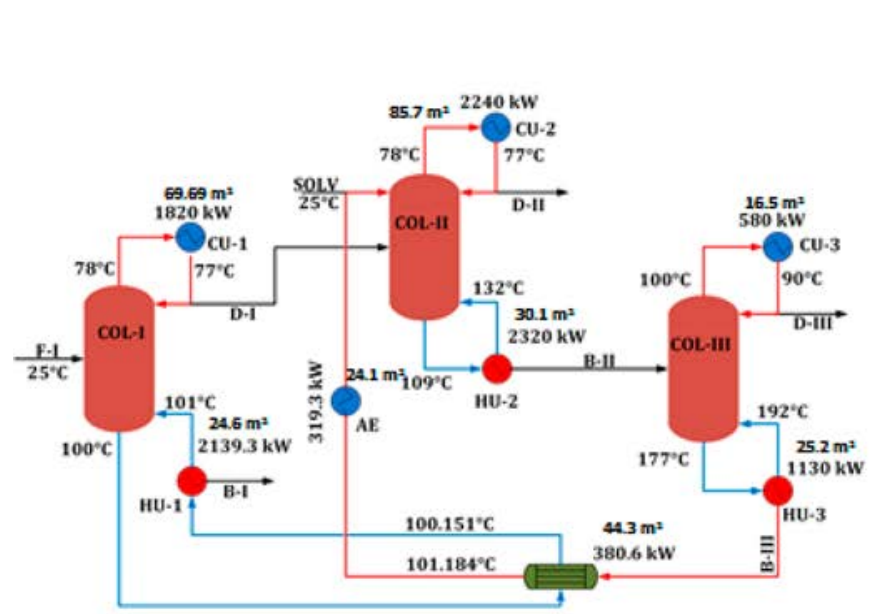

A) CSS-EI-I

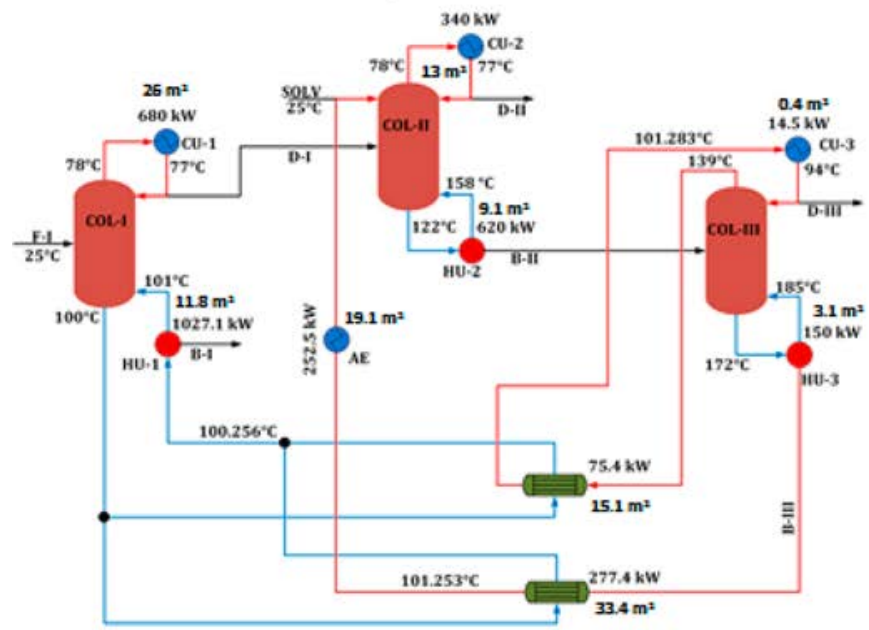

C) CSS-EI-III

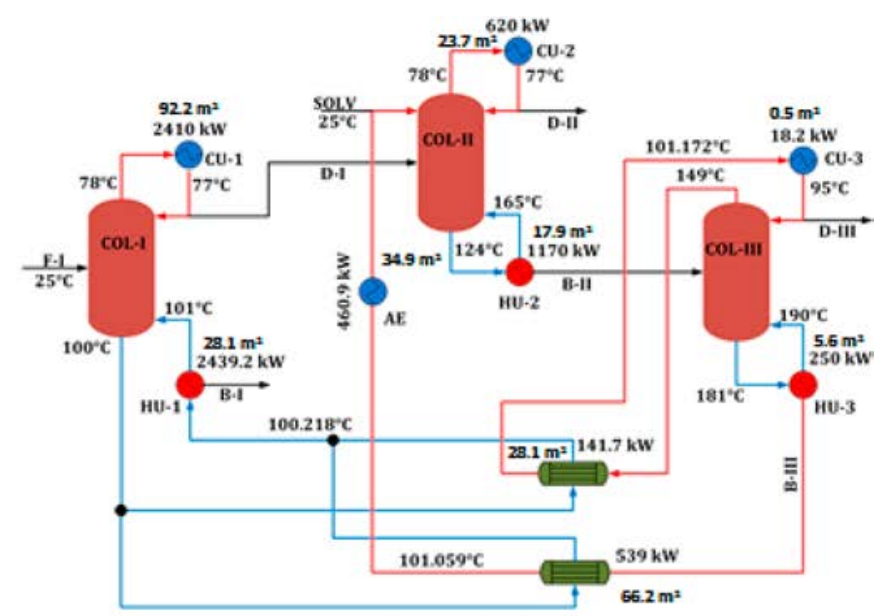

B) CSS-EI-II

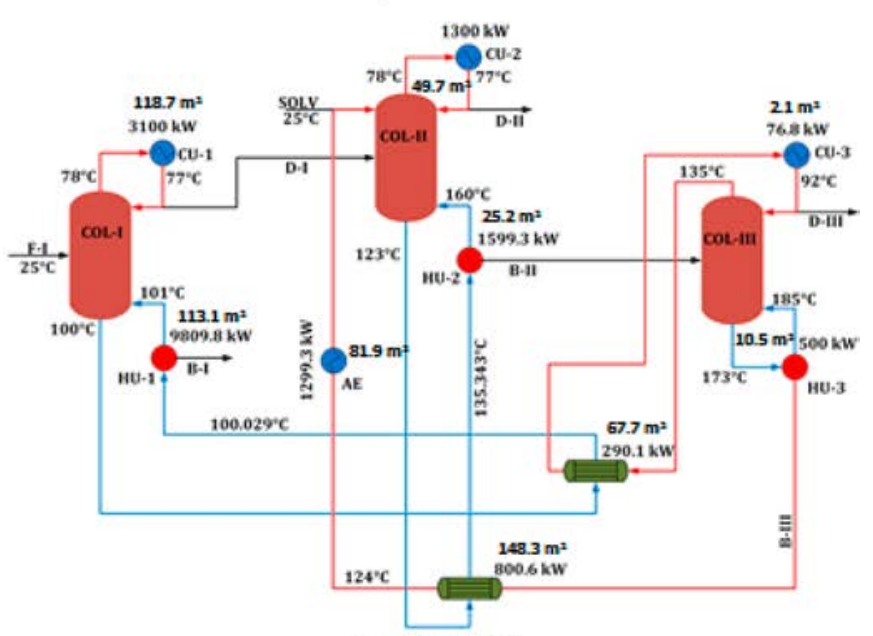

D) CSS-EI-IV

Figure 9. Conventional separation sequence with mass and energy integration based on the SYNHEAT model.

energy consumptions with and without energy integration by the HEN-ORC model for sequences CSS and OSS, and Table 6 shows the associated costs for both sequences.
Figures 9 and 11 present the CSS-EI and OSS-EI sequences, respectively, which incorporate mass and energy integration without considering the ORC. These show significant 


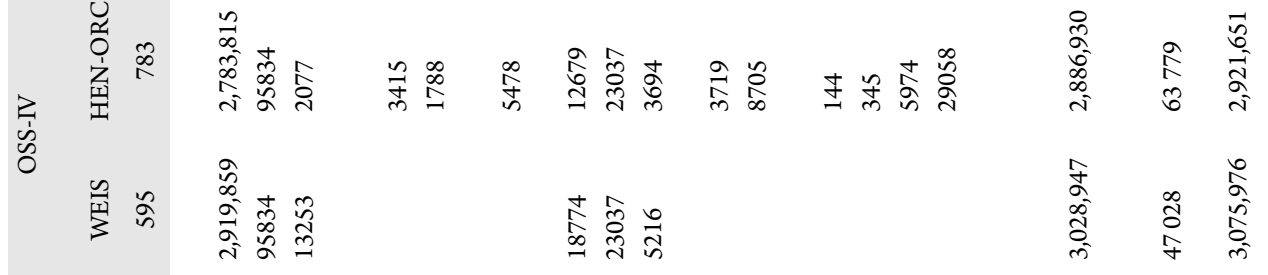

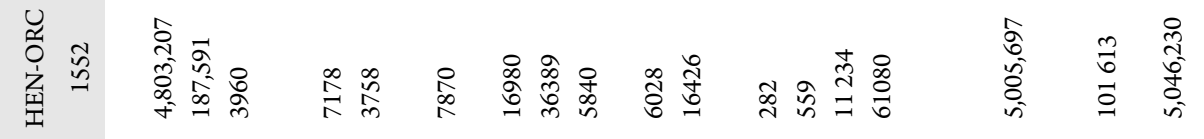

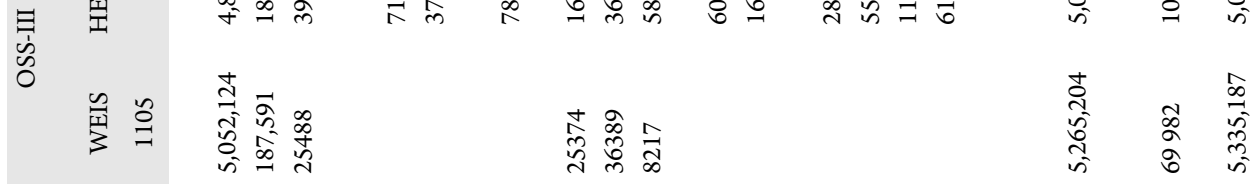

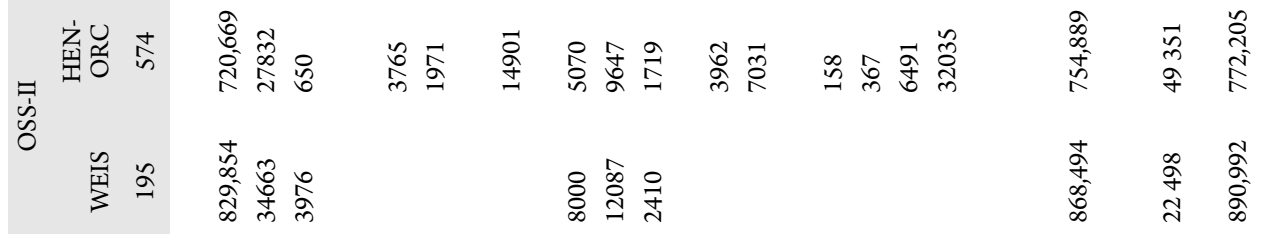

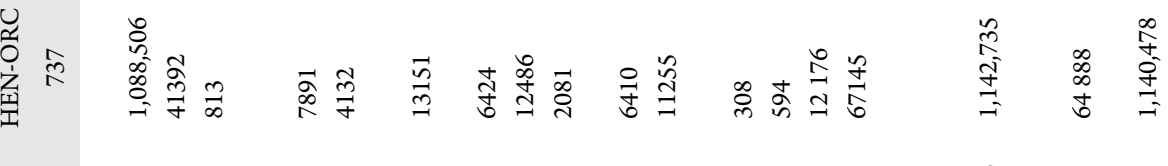

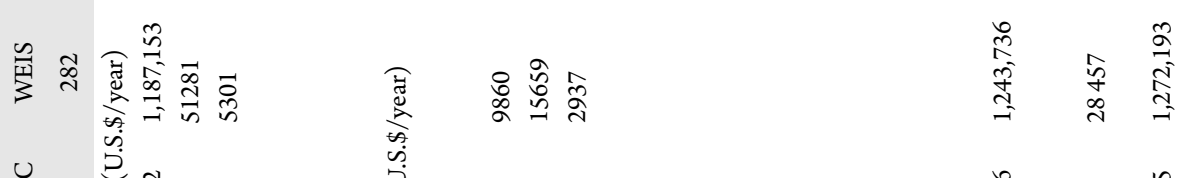

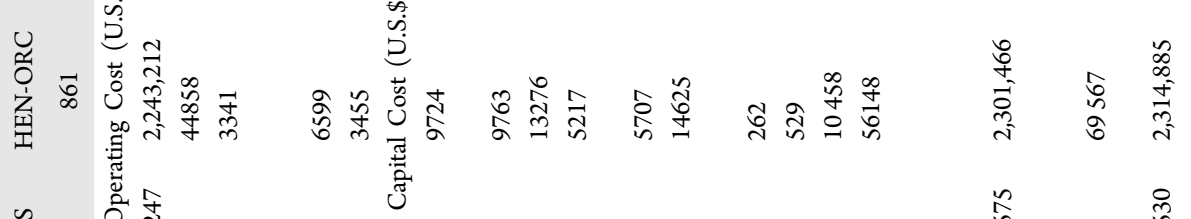

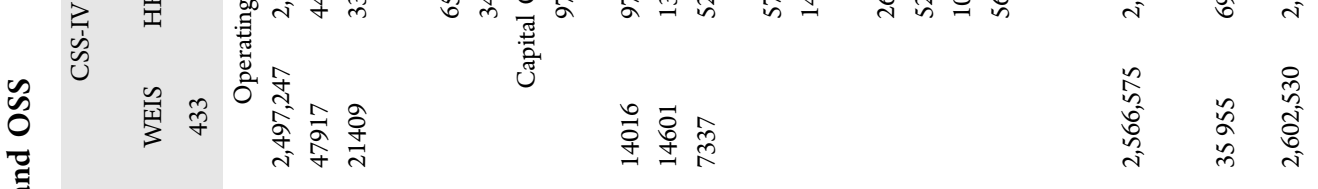

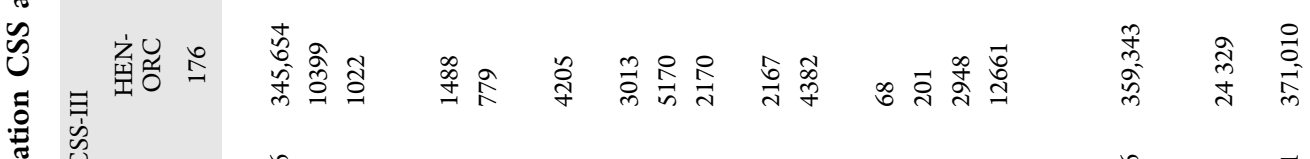

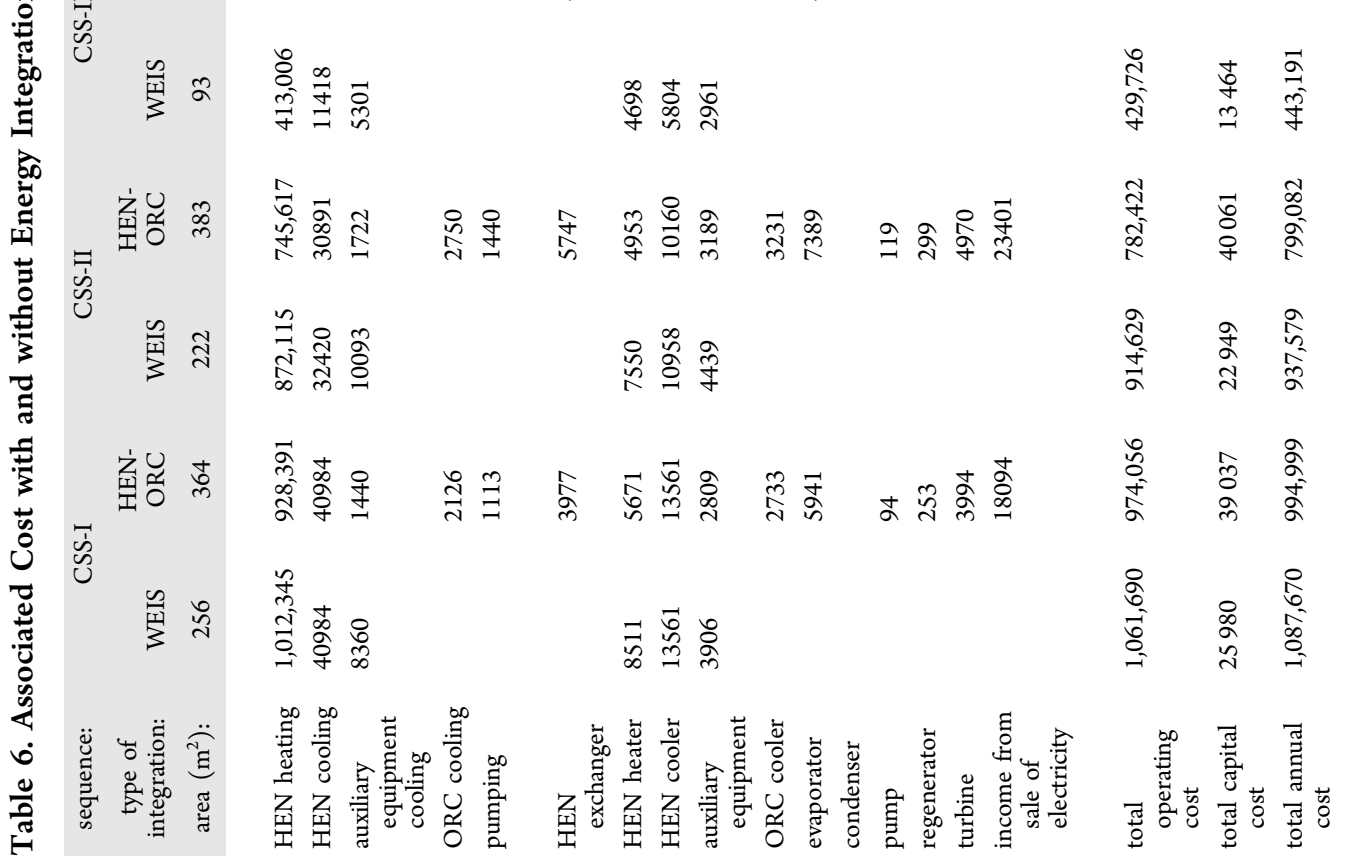



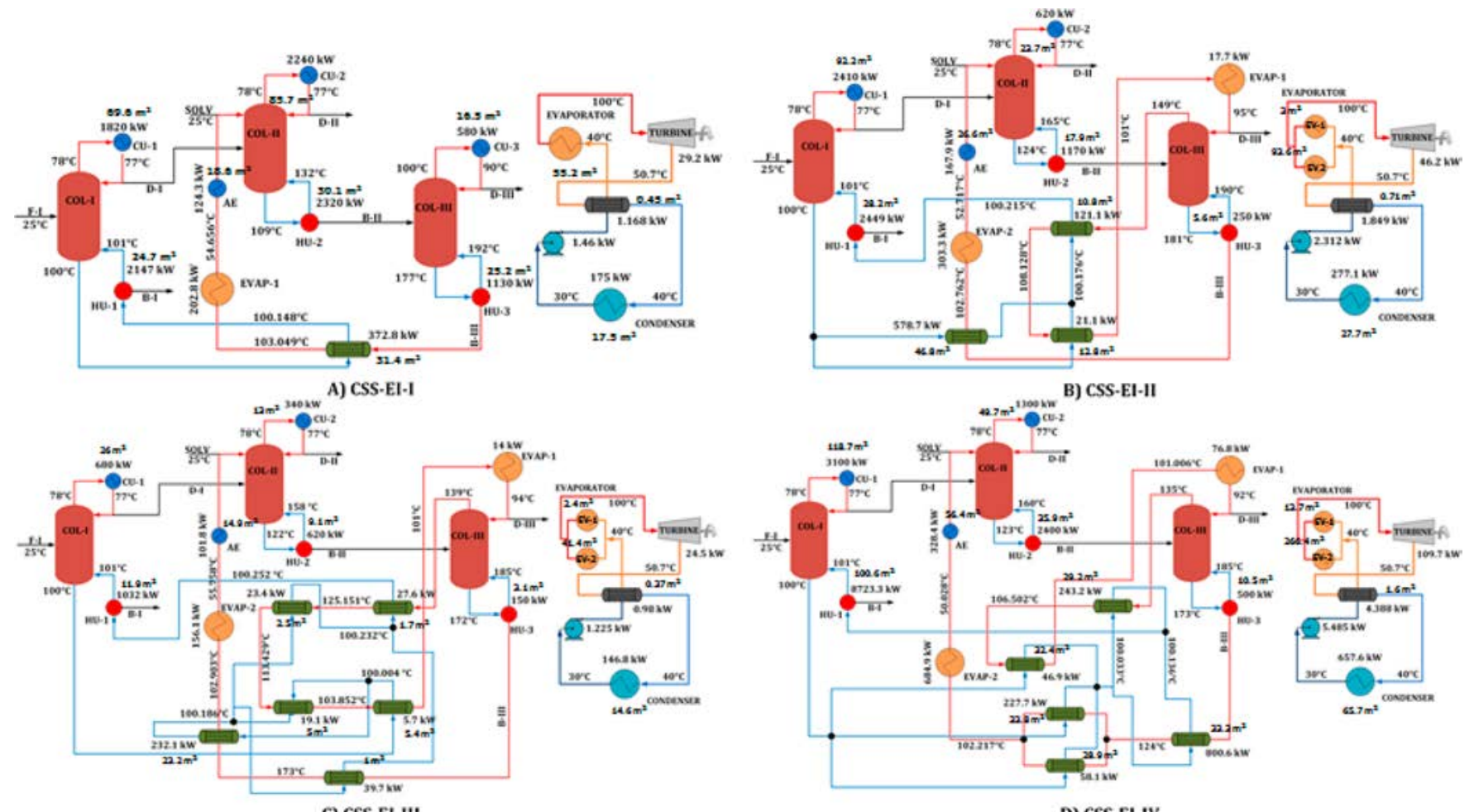

Figure 10. Conventional separation sequence with mass and energy integration based on the HEN-ORC integration.

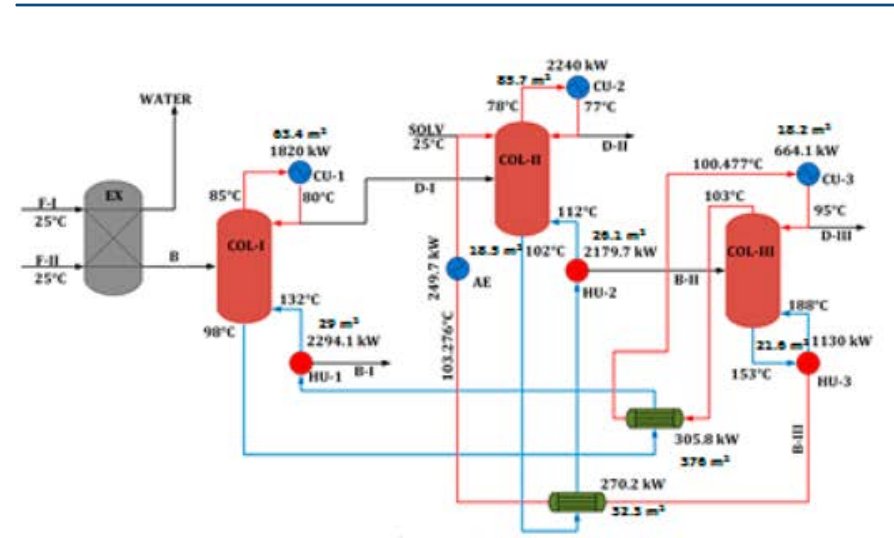

A) OSS-EI-I

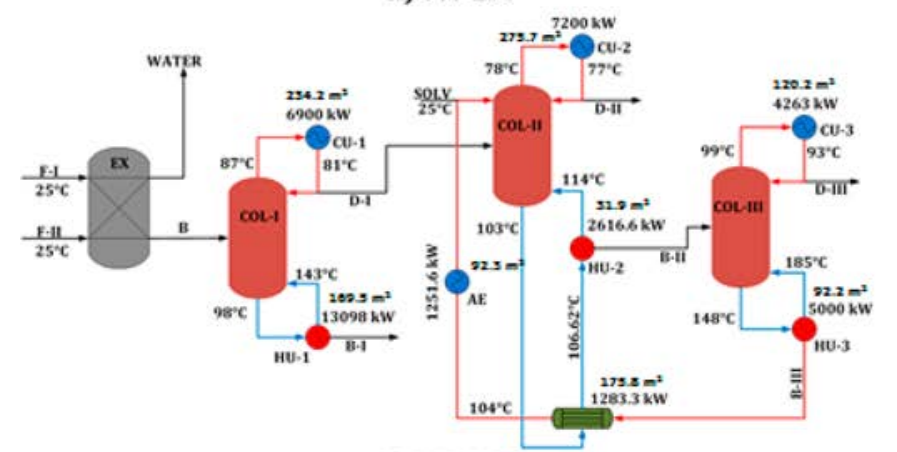

C) OSS-EI-III

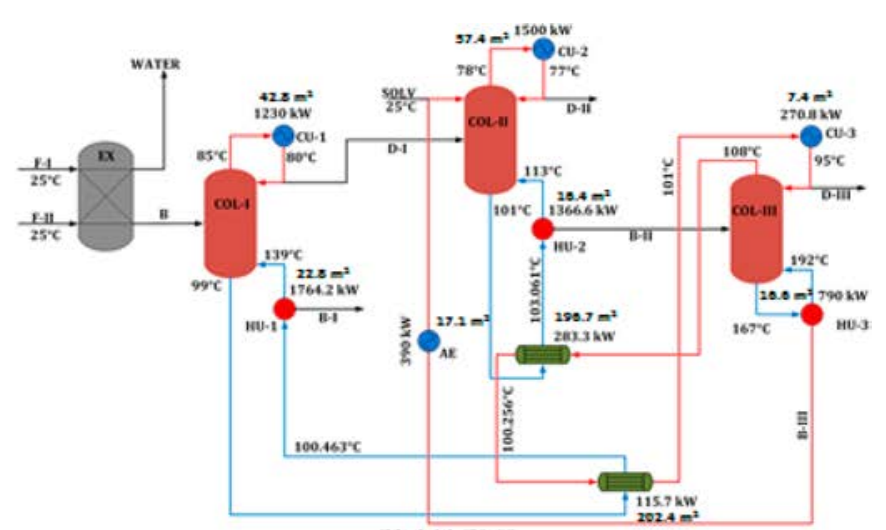

B) OSS-EI-II

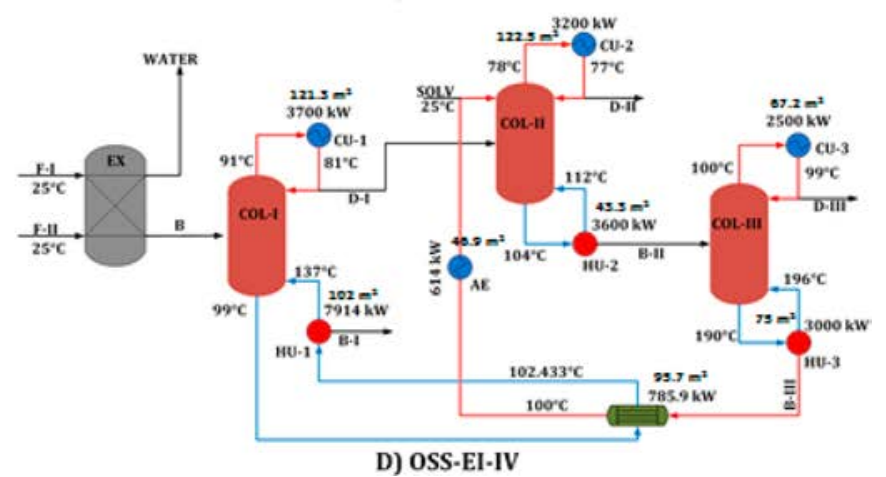

Figure 11. Hybrid configuration based on liquid-liquid extraction and extractive distillation with mass and energy integration using SYNHEAT model.

reductions in the associated cost with respect to the WEIS sequences; therefore, the HEN-ORC approach is applied to yield additional energy savings. Figures 10 and 12 show the optimal configuration of the previous optimized designs
(CSS-EI and OSS-EI), where the HEN-ORC model is applied to yield the following additional energy savings. Note that the solution of Figure 10 presents the highest heating utility consumption $(0.13 \%$ for sequence I, $0.25 \%$ for sequence II, 

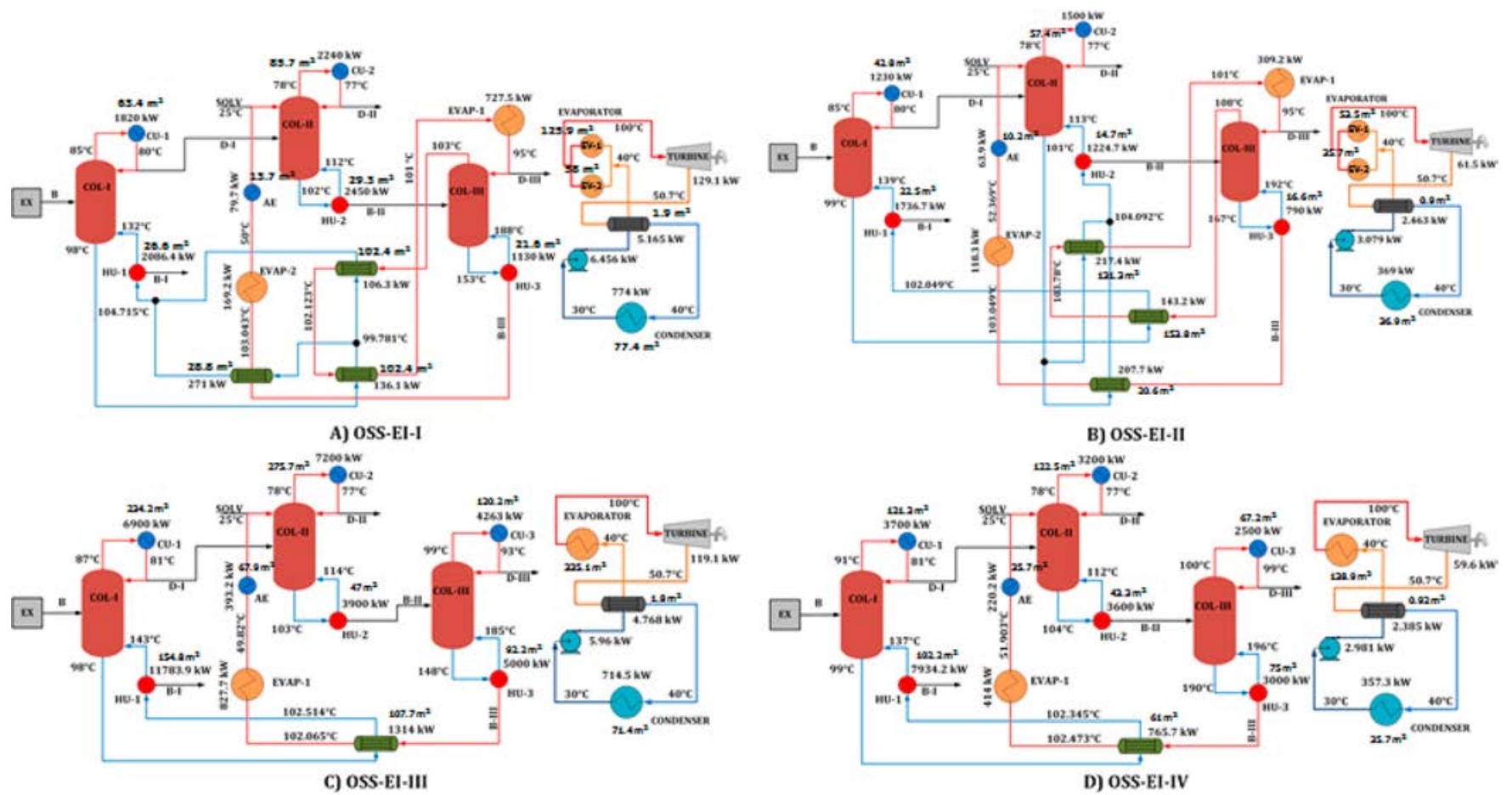

Figure 12. Hybrid configuration based on liquid-liquid extraction and extractive distillation with mass and energy integration applying HEN-ORC model.

Table 7. Energy Requirements for CSS-EI and OSS-EI

\begin{tabular}{|c|c|c|c|c|c|c|c|c|}
\hline \multirow[b]{2}{*}{ concept/sequence: } & \multicolumn{4}{|c|}{ CSS-EI } & \multicolumn{4}{|c|}{ OSS-EI } \\
\hline & I & II & III & IV & I & II & III & IV \\
\hline \multicolumn{9}{|c|}{ SYNHEAT Model (kW) } \\
\hline heating & 5589.3 & 3859.2 & 1797.1 & 11909.1 & 5603.8 & 3920.8 & 20714.6 & 14514 \\
\hline cooling & 4640 & 3048.2 & 1034.5 & 4476.8 & $4,724.1$ & 3000.8 & 18363 & 9400 \\
\hline auxiliary equipment & 319.3 & 460.9 & 252.5 & 1299.3 & 249.7 & 390 & 1251.6 & 614 \\
\hline no. of exchangers & 1 & 2 & 2 & 2 & 2 & 2 & 1 & 1 \\
\hline total heat transferred in HEN & 380.6 & 680.7 & 352.8 & 1090.8 & 576.1 & 399.1 & 1283.3 & 785.9 \\
\hline \multicolumn{9}{|c|}{ HEN-ORC Model (kW) } \\
\hline heating & 5597.1 & 3869 & 1802 & 11623.2 & 5666.4 & 3751.5 & 20683.9 & 14534.2 \\
\hline cooling & 4640 & 3030 & 1020 & 4400 & 4060 & 2730 & 18363 & 9400 \\
\hline auxiliary equipment & 124.3 & 167.9 & 101.8 & 328.4 & 79.7 & 69.915 & 393.2 & 220.2 \\
\hline no. of exchangers & 1 & 3 & 6 & 5 & 3 & 3 & 1 & 1 \\
\hline total heat transferred with HEN & 372.8 & 670.9 & 347.9 & 1376.6 & 513.5 & 568.5 & 1314 & 765.7 \\
\hline total heat transferred to ORC & 202.8 & 321 & 170.1 & 761.8 & 896.7 & 427.5 & 827.7 & 414 \\
\hline power produced & 29.2 & 46.2 & 24.5 & 109.7 & 129.1 & 61.5 & 119.1 & 59.6 \\
\hline \multicolumn{9}{|c|}{ Savings (\%) } \\
\hline heating & -0.13 & -0.25 & -0.27 & 2.4 & -1.11 & 4.31 & 0.14 & -0.13 \\
\hline cooling & 0 & 0.59 & 1.4 & 1.71 & 14.05 & 9.02 & 0 & 0 \\
\hline auxiliary equipment & 61.07 & 63.57 & 59.68 & 74.72 & 68.08 & 82.07 & 68.58 & 64.13 \\
\hline
\end{tabular}

and $0.27 \%$ for sequence III) and contains the greatest number of heat exchangers, but this solution has energy savings for cooling utility between 0.59 and $1.71 \%$ and for the auxiliary equipment between 59.68 and $74.72 \%$. Moreover, the design obtained produces electric power of 29.2, 46.2, 24.5, and $109.7 \mathrm{~kW}$ for CSS-EI I, II, III, and IV, respectively; therefore, the incomes produced are between U.S.\$2964/year and U.S.\$10600/year. The return on investment for the ORC is $108,117,105$, and $135 \%$ for sequences I, II, III, and IV, respectively. The total annual costs obtained are 0.52, 1.30, 1.34, and 6.9\% lower than the solutions when the SYNHEAT model is used (Figure 9).
The solutions of Figure 12 show energy savings for heating ( $4.31 \%$ for sequence II and $0.14 \%$ for sequences III), cooling (14.05\% for sequence I and $9.02 \%$ for sequence II), and the auxiliary equipment $(68.08 \%$ for sequence I, $82.07 \%$ for sequence II, $68.58 \%$ for sequence III, and $64.13 \%$ for sequence IV). The return on investment for the ORC is $157,134,134$, and $120 \%$ for sequences I, II, III, and IV, respectively. The produced electric power is $129.1 \mathrm{~kW}$ for sequence I, $61.5 \mathrm{~kW}$ for sequence II, $119.1 \mathrm{~kW}$ for sequence III, and $59.6 \mathrm{~kW}$ for sequence IV. The achieved revenues are between U.S.\$6312/ year and U.S.\$12176/year, yielding total annual separation costs $2.98,7.15,0.96$, and $0.46 \%$ lower than the solutions that 


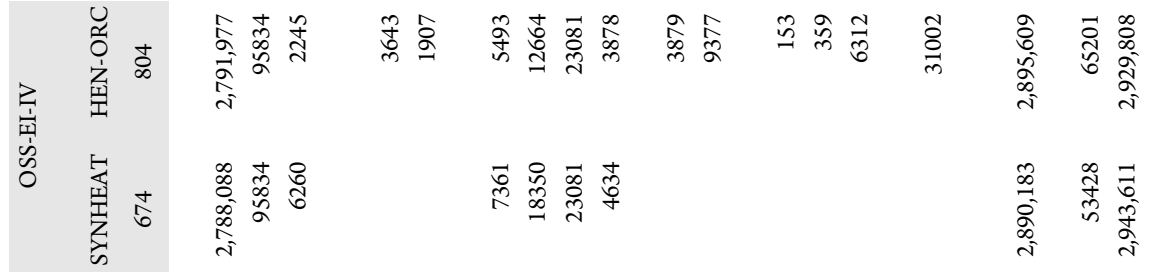

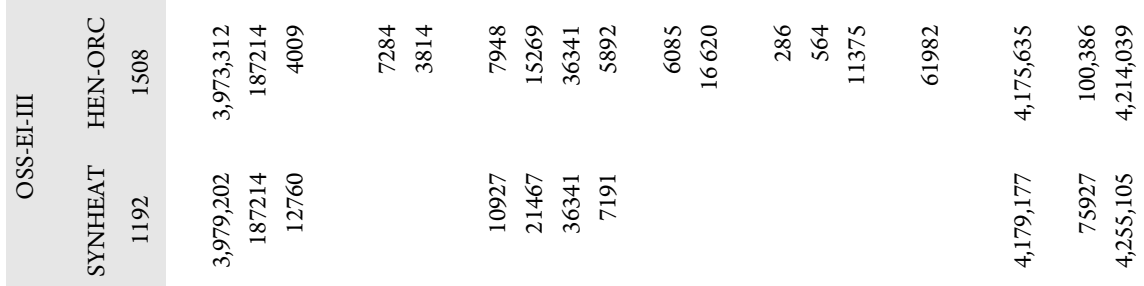

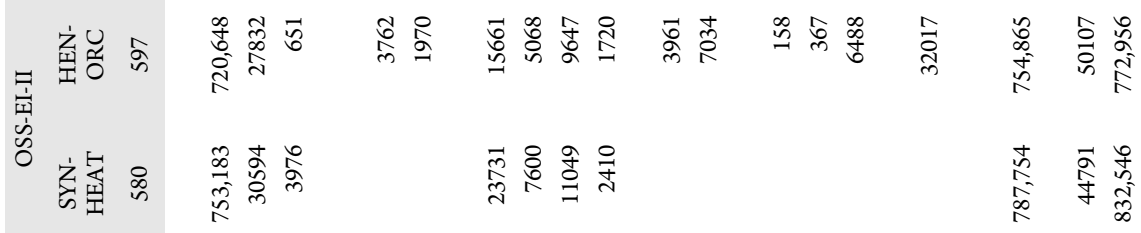

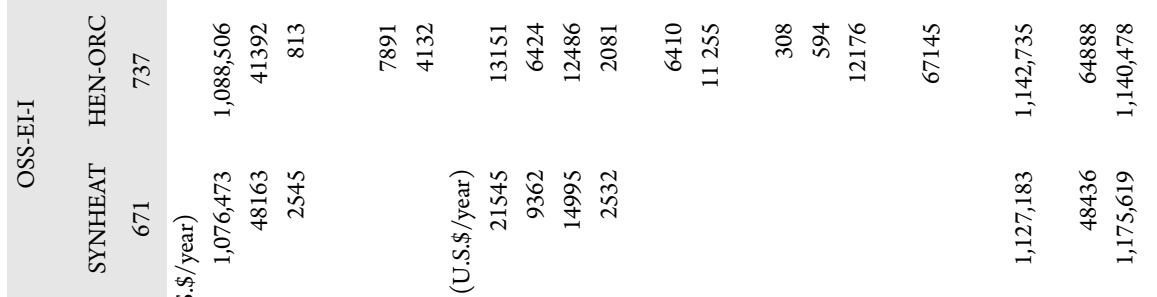

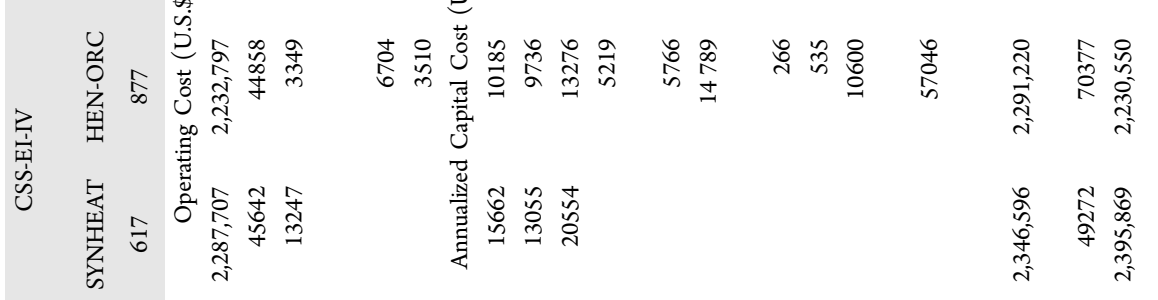

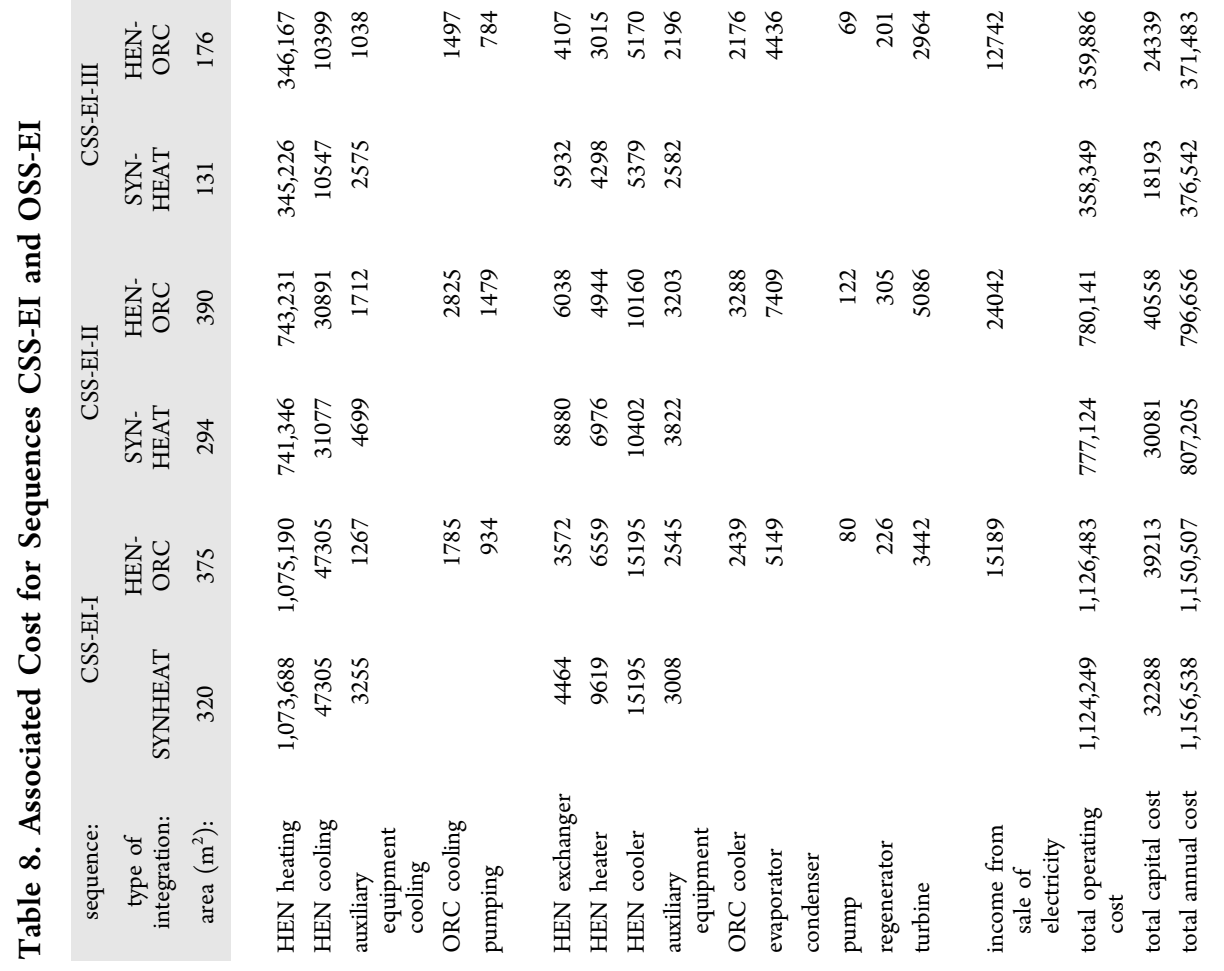


consider the SYNHEAT model. Table 7 presents the energy consumptions for the sequences CSS-EI and OSS-EI, and Table 8 shows the associated costs for both sequences.

It should be noticed that the areas in the solutions of the HEN-ORC model are greater than the ones of the solutions by the WEIS solution and the one that considers the SYNHEAT model; nevertheless, the solutions by the HEN-ORC model present total annual separation costs lower and this last one generates electric power from the waste heat of the process.

\section{CONCLUSIONS}

In this paper has been presented one option to reduce the energy requirements in the bioethanol separation process to yield biogasoline. In this case, the possible energy integration through the simultaneous synthesis of HEN integrated to an ORC has been considered. This integrated scheme improves the energy recovery process because this considers simultaneously the energy integration between process streams, and at the same time this includes the possible recovery of waste heat at low temperature to produce electric power. The proposed integrated scheme was applied to several bioethanol separation processes, and the results have shown that the proposed integrated HEN-ORC scheme produces significant reductions in the required utilities, which improves the overall energy efficiency. Furthermore, the electric power produced from the waste heat recovered is significant, and this reduces significantly the total bioethanol separation cost due to the sale of the electric power produced. Finally, there is required a study for the dynamic behavior of the integrated system to determine the controllability and operability of the system.

\section{AUTHOR INFORMATION}

\section{Corresponding Author}

*(J.M.P.-O.) E-mail: jmponce@umich.mx. Phone: +52 443 3223500, ext. 1277. Fax: +52 4433273584.

\section{Notes}

The authors declare no competing financial interest.

\section{ACKNOWLEDGMENTS}

This research was supported by SAGARPA-CONACyT (Grant 174560).

\section{REFERENCES}

(1) Sadhukhan, J.; Ng, K. S. Economic and European Union environmental sustainability criteria assessment of bio-oil-based biofuel systems: refinery integration cases. Ind. Eng. Chem. Res. 2011, 50, 6794-6808.

(2) Akgul, O.; Zamboni, A.; Bezzo, F.; Shah, N.; Papageorgiou, L. G. Optimization-based approaches for bioethanol supply chains. Ind. Eng. Chem. Res. 2010, 50, 4927-4938.

(3) Solomon, B. D.; Barnes, J. R.; Halvorsen, K. E. Grain and cellulosic ethanol: history, economics, and energy policy. Biomass Bioenergy 2007, 31 (6), 416-425.

(4) Sosa, M. A.; Chovau, S.; Van der Bruggen, B.; Espinosa, J. Ethanol production from corn contaminated with fumonisins: a preliminary economic analysis including novel processing alternatives. Ind. Eng. Chem. Res. 2013, 52, 7504-7513.

(5) Sapp, M. Europe's ethanol affair. Biofuels, Bioprod. Biorefining 2007, 1 (2), 88-91.

(6) Hoch, P. M.; Espinosa, J. Conceptual design and simulation tools applied to the evolutionary optimization of a bioethanol purification plant. Ind. Eng. Chem. Res. 2008, 47, 7381-7389.
(7) Chávez-Islas, L. M.; Vasquez-Medrano, R.; Flores-Tlacuáhuac, A. Optimal molecular design of ionic liquids for high-purity bioethanol production. Ind. Eng. Chem. Res. 2011, 50, 5153-5168.

(8) Kanchanalai, P.; Lively, R. P.; Realff, M. J.; Kawajiri, Y. Cost and energy savings using an optimal design of reverse osmosis membrane pretreatment for dilute bioethanol purification. Ind. Eng. Chem. Res. 2013, 52, 11132-11141.

(9) Errico, M.; Rong, B.-G.; Tola, G.; Spano, M. Optimal synthesis of distillation systems for bioethanol separation. Part 1: Extractive distillation with simple columns. Ind. Eng. Chem. Res. 2013, 52, 16121619.

(10) Errico, M.; Rong, B.-G.; Tola, G.; Spano, M. Optimal synthesis of distillation systems for bioethanol separation. Part 2: Extractive distillation with complex columns. Ind. Eng. Chem. Res. 2013, 52, $1620-1626$

(11) Black, C. Distillation modeling of ethanol recovery and dehydration processes for ethanol and gasohol. Chem. Eng. Prog. 1980, 76 (9), 78-85.

(12) Barba, D.; Brandani, V.; Di Giacomo, G. Hyperazeotropic ethanol salted-out by extractive distillation. Theoretical evaluation and experimental check. Chem. Eng. Sci. 1985, 40 (12), 2287-2292.

(13) Iliuta, M. C.; Thyrion, F. C. Effect of calcium chloride on the isobaric vapor-liquid equilibrium of 1-propanol + water. J. Chem. Eng. Data 1996, 41 (3), 402-408.

(14) Sun, T.; Bullock, K. R.; Teja, A. S. Correlation and prediction of salt effects on vapor-liquid equilibrium in alcohol-water-salt systems. Fluid Phase Equilib. 2004, 219 (2), 257-264.

(15) Further, W. F. Extractive distillation by salt effect. Chem. Eng. Commun. 1992, 116 (1), 35-40.

(16) Balat, M.; Balat, H. Recent trends in global production and utilization of bio-ethanol fuel. Appl. Energy 2009, 86 (11), 2273-2282.

(17) Reith, J. H.; Veenkamp, J. M.; van Ree, R. Co-production of bioethanol, electricity and heat from biomass wastes: potential and R\&D issues. In Contribution to the First European Conference on Agriculture and Renewable Energy; Netherlands Energy Research Foundation ECN: Petten, The Netherlands, 2001.

(18) Linnhoff, B. A. User Guide on Process Integration for the Efficient Use of Energy; Institution of Chemical Engineers: London, UK, 1982.

(19) Furman, K. C.; Sahinidis, N. V. A critical review and annotated bibliography for heat exchanger network synthesis in the 20th century. Ind. Eng. Chem. Res. 2002, 41 (10), 2335-2370.

(20) Konukman, A. E. S.; Camurdan, M. C.; Akman, U. Simultaneous flexibility targeting and synthesis of minimum-utility heat-exchanger networks with superstructure-based MILP formulation. Chem. Eng. Process.: Process Intensification 2002, 41 (6), 501-518.

(21) Mizutani, F. T.; Pessoa, F. L. P.; Queiroz, E. M.; Hauan, S.; Grossmann, I. E. Mathematical programming model for heatexchanger network synthesis including detailed heat exchanger designs. 2. Networks synthesis. Ind. Eng. Chem. Res. 2003, 42 (17), 4019-4027.

(22) Serna-González, M.; Ponce-Ortega, J. M.; Jiménez-Gutiérrez, A. Two-level optimization algorithm for heat exchanger networks including pressure drop considerations. Ind. Eng. Chem. Res. 2004, 43 (21), 6766-6773.

(23) Verheyen, W.; Zhang, N. Design of flexible heat exchanger network for multi-period operation. Chem. Eng. Sci. 2006, 61 (23), $7730-7753$.

(24) Jiménez-Gutiérrez, A.; Ponce-Ortega, J. M.; Serna-González, M. Synthesis of heat exchanger networks including pressure drops considerations and detailed design of heat exchangers: a review. Trends Heat Mass Transfer 2009, 11, 1-16.

(25) Morar, M.; Agachi, P. S. Review: Important contributions in development and improvement of the heat integration techniques. Comput. Chem. Eng. 2010, 34 (8), 1171-1179.

(26) Vázquez-Ojeda, M.; Segovia-Hernández, J. G.; Ponce-Ortega, J. $M$. Incorporation of mass and energy integration in the optimal bioethanol separation process. Chem. Eng. Technol. 2013, 36 (11), 110. 
(27) Yee, T. F.; Grossmann, I. E. Simultaneous optimization models for heat integration - II. Heat exchanger network synthesis. Comput. Chem. Eng. 1990, 14 (10), 1165-1184.

(28) Grossman, I. E. Mixed-integer optimization techniques for algorithmic process synthesis. In Advances in Chemical Engineering, Process Synthesis; Anderson, J. L., Ed.; Academic Press: New York, 1996; Vol. 23, pp 171-246.

(29) Ma, K. L.; Hui, C. W.; Yee, T. F. Constant approach temperature model for HEN retrofit. Appl. Therm. Eng. 2000, 20 (1516), $1505-1533$.

(30) Ponce-Ortega, J. M.; Jiménez-Gutiérrez, A.; Grossmann, I. E. Simultaneous retrofit and heat integration of chemical processes. Ind. Eng. Chem. Res. 2008, 47 (15), 5512-5528.

(31) López-Maldonado, L. A.; Ponce-Ortega, J. M.; SegoviaHernández, J. G. Multiobjective synthesis of heat exchanger networks minimizing the total annual cost and the environmental impact. Appl. Therm. Eng. 2011, 31 (6-7), 1099-1113.

(32) Lee, K. M.; Kuo, S. F.; Chien, M. L.; Shih, Y. S. Parameters analysis on organic Rankine cycle energy recovery system. Energy Convers. Manage. 1988, 28 (2), 129-136.

(33) Hung, T. C.; Shai, T. Y.; Wang, S. K. A review of organic Rankine cycles (ORCs) for the recovery of low-grade waste heat. Energy 1997, 22 (7), 661-667.

(34) Hung, T. C. Waste heat recovery of organic Rankine cycle using dry fluids. Energy Convers. Manage. 2001, 42 (5), 539-553.

(35) Hettiarachchi, M. H. D.; Golubovic, M.; Worek, W. M.; Ikegami, Y. Optimum design criteria for an organic Rankine cycle using lowtemperature geothermal heat sources. Energy 2007, 32 (9), 16981706.

(36) Dai, Y.; Wang, J.; Gao, L. Parametric optimization and comparative study of organic Rankine cycle (ORC) for low grade waste heat recovery. Energy Convers. Manage. 2009, 50 (3), 576-582.

(37) Desai, N. B.; Bandyopadhyay, S. Process integration of organic Rankine cycle. Energy 2009, 34 (10), 1674-1686.

(38) Hipólito-Valencia, B. J.; Rubio-Castro, E.; Ponce-Ortega, J. M.; Serna-González, M.; Nápoles-Rivera, F.; El-Halwagi, M. M. Optimal integration of organic Rankine cycle with industrial processes. Energy Convers. Manage. 2013, 73, 285-302.

(39) Hipólito-Valencia, B. J.; Rubio-Castro, E.; Ponce-Ortega, J. M.; Serna-González, M.; Nápoles-Rivera, F.; El-Halwagi, M. M. Optimal design of inter-plant waste energy integration. Appl. Therm. Eng. 2013, 62, 633-652.

(40) Hipólito-Valencia, B. J.; Lira-Barragán, L. F.; Ponce-Ortega, J. M.; Serna-González, M.; El-Halwagi, M. M. Multiobjective design of interplant trigeneration systems. AIChE J. 2014, 60, 213-236.

(41) Vázquez-Ojeda, M.; Segovia-Hernández, J. G.; Hernández, S.; Hernández-Aguirre, A.; Kiss, A. A. Design and optimization of an ethanol dehydration process using stochastic methods. Sep. Purif. Technol. 2013, 105, 90-97.

(42) Segovia-Hernandez, J. G.; Vázquez-Ojeda, M.; Gómez-Castro, F. I.; Ramírez-Márquez, C.; Errico, M.; Tronci, S.; Rong, B.-G. Process control analysis for intensified bioethanol separation systems. Chem. Eng. Process.: Process Intensification 2014, 75, 119-125.

(43) Brooke, A.; Kendrick, D.; Meeruas, A.; Raman, R. GAMS Language Guide; GAMS Development Corp.: Washington, DC, USA, 2013. 